\title{
Article \\ Phosphoprotein Phosphatase 1 but Not 2A Activity Modulates Coupled-Clock Mechanisms to Impact on Intrinsic Automaticity of Sinoatrial Nodal Pacemaker Cells
}

\author{
Syevda Tagirova Sirenko ${ }^{\dagger}$, Ihor Zahanich ${ }^{\dagger}$, Yue Li, Yevgeniya O. Lukyanenko $\left({ }^{\circledR}\right.$, Alexey E. Lyashkov, \\ Bruce D. Ziman, Kirill V. Tarasov, Antoine Younes, Daniel R. Riordon, Yelena S. Tarasova, Dongmei Yang, \\ Tatiana M. Vinogradova, Victor A. Maltsev (1) and Edward G. Lakatta *
}

check for updates

Citation: Sirenko, S.T.; Zahanich, I.; Li, Y.; Lukyanenko, Y.O.; Lyashkov, A.E.; Ziman, B.D.; Tarasov, K.V.; Younes, A.; Riordon, D.R.; Tarasova, Y.S.; et al. Phosphoprotein Phosphatase 1 but Not 2A Activity Modulates Coupled-Clock

Mechanisms to Impact on Intrinsic Automaticity of Sinoatrial Nodal Pacemaker Cells. Cells 2021, 10, 3106. https://doi.org/10.3390/cells10113106

Academic Editor: Alexander G. Obukhov

Received: 20 September 2021 Accepted: 5 November 2021 Published: 10 November 2021

Publisher's Note: MDPI stays neutral with regard to jurisdictional claims in published maps and institutional affiliations.

Copyright: () 2021 by the authors. Licensee MDPI, Basel, Switzerland. This article is an open access article distributed under the terms and conditions of the Creative Commons Attribution (CC BY) license (https:// creativecommons.org/licenses/by/ $4.0 /)$.
Laboratory of Cardiovascular Science, National Institute on Aging, NIH, Baltimore, MD 21224, USA; syevda.tagirova@nih.gov (S.T.S.); zahanich@gmail.com (I.Z.); yueli@som.umaryland.edu (Y.L.); lukyanenkoy@nia.nih.gov (Y.O.L.); alexey.lyashkov@nih.gov (A.E.L.); zimanb@grc.nia.nih.gov (B.D.Z.); tarasovkv@mail.nih.gov (K.V.T.); antoine.younes@wanadoo.fr (A.Y.); riordond@grc.nia.nih.gov (D.R.R.); tarasovay@grc.nia.nih.gov (Y.S.T.); dongmei.brochet@nih.gov (D.Y.); vinogradovat@grc.nia.nih.gov (T.M.V.); maltsevvi@mail.nih.gov (V.A.M.)

* Correspondence: lakattae@grc.nia.nih.gov

+ These authors contributed to this work equally.

Abstract: Spontaneous AP (action potential) firing of sinoatrial nodal cells (SANC) is critically dependent on protein kinase $\mathrm{A}$ (PKA) and $\mathrm{Ca}^{2+} /$ calmodulin-dependent protein kinase II (CaMKII)dependent protein phosphorylation, which are required for the generation of spontaneous, diastolic local $\mathrm{Ca}^{2+}$ releases (LCRs). Although phosphoprotein phosphatases (PP) regulate protein phosphorylation, the expression level of PPs and phosphatase inhibitors in SANC and the impact of phosphatase inhibition on the spontaneous LCRs and other players of the oscillatory coupled-clock system is unknown. Here, we show that rabbit SANC express both PP1, PP2A, and endogenous PP inhibitors I-1 (PPI-1), dopamine and cyclic adenosine $3^{\prime}, 5^{\prime}$-monophosphate (cAMP)-regulated phosphoprotein (DARPP-32), kinase C-enhanced PP1 inhibitor (KEPI). Application of Calyculin A, (CyA), a PPs inhibitor, to intact, freshly isolated single SANC: (1) significantly increased phospholamban (PLB) phosphorylation (by 2-3-fold) at both CaMKII-dependent $\mathrm{Thr}^{17}$ and PKA-dependent Ser ${ }^{16}$ sites, in a time and concentration dependent manner; (2) increased ryanodine receptor (RyR) phosphorylation at the $\mathrm{Ser}^{2809}$ site; (3) substantially increased sarcoplasmic reticulum (SR) $\mathrm{Ca}^{2+}$ load; (4) augmented L-type $\mathrm{Ca}^{2+}$ current amplitude; (5) augmented LCR's characteristics and decreased LCR period in intact and permeabilized SANC, and (6) increased the spontaneous basal AP firing rate. In contrast, the selective PP2A inhibitor okadaic acid $(100 \mathrm{nmol} / \mathrm{L})$ had no significant effect on spontaneous AP firing, LCR parameters, or PLB phosphorylation. Application of purified PP1 to permeabilized SANC suppressed LCR, whereas purified PP2A had no effect on LCR characteristics. Our numerical model simulations demonstrated that PP inhibition increases AP firing rate via a coupled-clock mechanism, including respective increases in the $\mathrm{SR} \mathrm{Ca}^{2+}$ pumping rate, L-type $\mathrm{Ca}^{2+}$ current, and $\mathrm{Na}^{+} / \mathrm{Ca}^{2+}$-exchanger current. Thus, PP1 and its endogenous inhibitors modulate the basal spontaneous firing rate of cardiac pacemaker cells by suppressing $\mathrm{SR} \mathrm{Ca}^{2+}$ cycling protein phosphorylation, the SR Ca ${ }^{2+}$ load and LCRs, and L-type $\mathrm{Ca}^{2+}$ current.

Keywords: sinoatrial node cells; local $\mathrm{Ca}^{2+}$ releases; phosphoprotein phosphatase; endogenous phosphatase inhibitors; calyculin A; okadaic acid; phospholamban; ryanodine receptors; L-type $\mathrm{Ca}^{2+}$ channels; numerical model

\section{Introduction}

The spontaneous action potential (AP) firing rate of sinoatrial nodal cells (SANC) is critically dependent on protein kinase A (PKA) and $\mathrm{Ca}^{2+} /$ calmodulin-dependent protein 
kinase II (CaMKII)-dependent phosphorylation [1-4] (Figure 1). SR-generated, subsarcolemmal, rhythmic, local $\mathrm{Ca}^{2+}$ releases (LCRs) via RyR activate an inward $\mathrm{Na}^{+} / \mathrm{Ca}^{2+}$ exchange current $\left(\mathrm{I}_{\mathrm{NCX}}\right)$, accelerating the rate of diastolic depolarization and leading to an increase in the spontaneous AP firing rate (Figure 1). Basal state phosphorylation of SR $\mathrm{Ca}^{2+}$ cycling proteins and L-type $\mathrm{Ca}^{2+}$ channels by PKA and CaMKII in SANC is markedly higher than in ventricular myocytes (VM) and both (CaMKII and PKA) are required for the generation of basal rhythmic LCRs and spontaneous AP firing of SANC [5].

\section{The Coupled-Clock System of SA node cell}

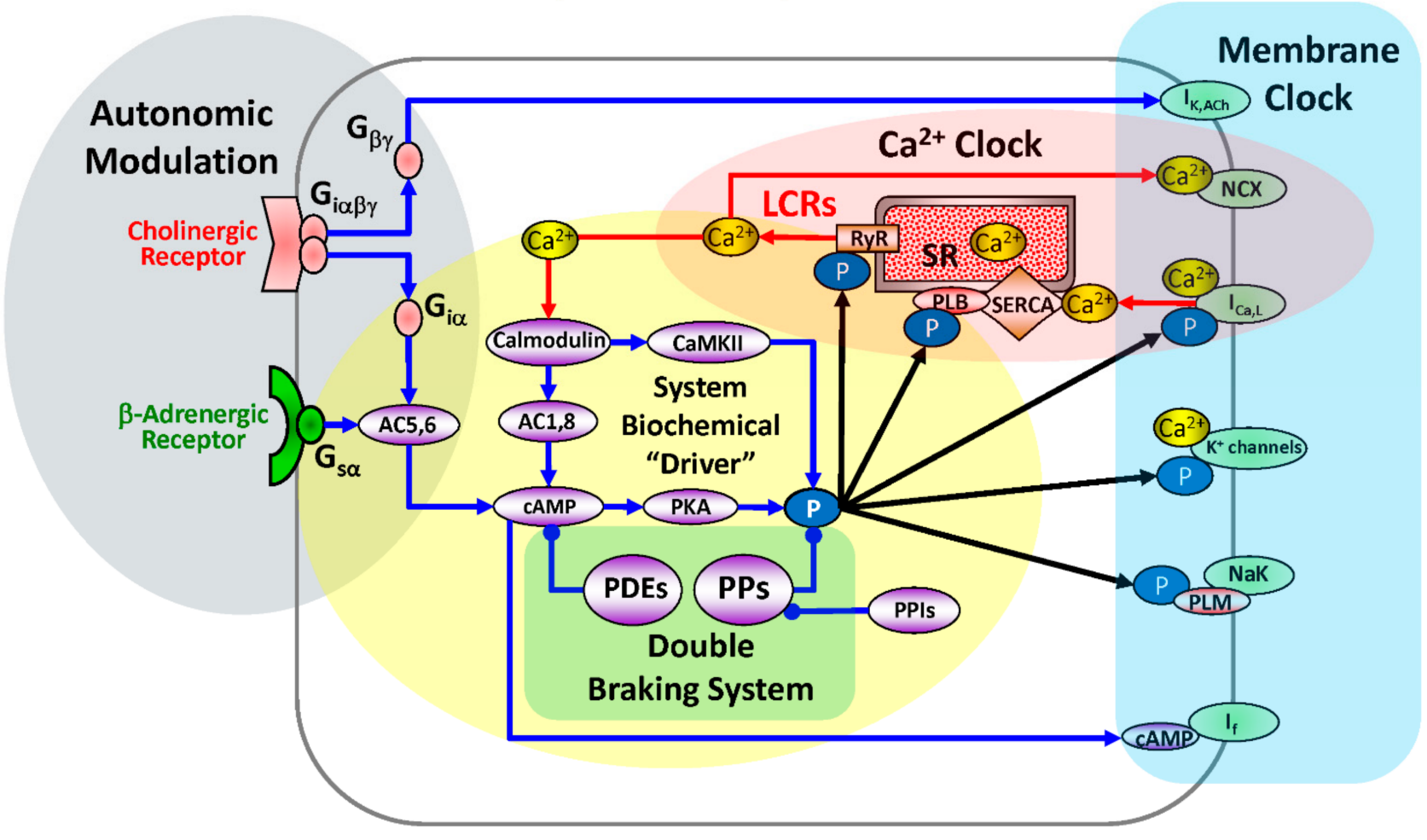

Figure 1. Schematic diagram of the coupled-clock system that includes four major sub-systems or functional modules: the sarcoplasmic reticulum, the $\mathrm{Ca}^{2+}$ clock; sarcolemmal ion channels and transporters, the membrane clock; biochemical drivers; and the autonomic modulation of the system components. The $\mathrm{Ca}^{2+}$ clock cycles $\mathrm{Ca}^{2+}$ via SR Ca ${ }^{2+}$ pump (SERCA) and $\mathrm{Ca}^{2+}$ release channels (RyRs). The membrane clock generates APs and interacts with the $\mathrm{Ca}^{2+}$ clock via multiple $\mathrm{Ca}^{2+}$-dependent mechanism, including NCX current that accelerates the diastolic depolarization. The system's biochemical driver is CAMP, which is generated by $\mathrm{Ca}^{2+}$-activated AC1and AC8 and leads to activation of PKA. PKA and CaMKII increase phosphorylation of clock proteins (black arrows). The autonomic nervous system modulates the clock system via $G$ protein-coupled receptor signaling. The cAMP level is kept in check by PDEs. The focus of the present study is to determine whether PPs, by keeping clock protein phosphorylation levels in check, form the double braking system with PDEs. Abbreviations: $\mathrm{I}_{\mathrm{K}, \mathrm{Ach}}$, acetylcholine-activated $\mathrm{K}^{+}$current; $\mathrm{NCX}, \mathrm{Na}^{+} / \mathrm{Ca}^{2+}$ exchanger; $\mathrm{I}_{\mathrm{CaL}}$, $\mathrm{L}_{\text {-type } \mathrm{Ca}^{2+}} \mathrm{current} \mathrm{K}^{+}$ channels, potassium channels; $\mathrm{I}_{\mathrm{f}}$, hyperpolarization-activated current; $\mathrm{Ca}^{2+}$, calcium ions; LCRs, local submembrane $\mathrm{Ca}^{2+}$ releases; RyR, ryanodine receptors; SR, sarcoplasmic reticulum; SERCA, SR Ca ${ }^{2+}$ ATPase; CaMKII, calcium-calmodulindependent protein kinase II; PLM, phospholemman; PLB, phospholamban; P, phosphorylation; PKA, protein kinase A; cAMP, cyclic adenosine 3', 5' -monophosphate; AC, adenylyl cyclase; Ggs $\alpha$, G-protein coupled receptors stimulatory alpha subunit; $G_{i \alpha}$, G-protein coupled receptors inhibitory alpha subunit; $G_{i \alpha \beta \gamma}$, G-protein coupled receptors inhibitory alpha, betta, gamma subunits; $\mathrm{G}_{\beta \gamma}$, G-protein coupled receptors beta, gamma subunits; PPs, phosphoprotein phosphatases; PPIs, phosphoprotein phosphatase inhibitors; PDEs, phosphodiesterases. 
The signaling cascade that activates basal protein kinase activity in SANC is "feedforward", i.e., $\mathrm{Ca}^{2+}$ release stimulates CaMKII and PKA (via $\mathrm{Ca}^{2+}$-calmodulin activated adenylyl cyclases (ACs)) and these kinases, by phosphorylating membrane clock proteins and SR $\mathrm{Ca}^{2+}$ cycling proteins, increase SR $\mathrm{Ca}^{2+}$ release, which further activates $\mathrm{Ca}^{2+}$ calmodulin activated ACs [6,7] and CaMKII (Figure 1).

The high basal level of phosphorylation in SANC is partly due to the increased level of cAMP, which is substantially higher in SANC than in ventricular myocytes $[1,3,7]$. Constitutive activity (in the absence of autonomic receptor activation) of $\mathrm{Ca}^{2+}$-dependent ACs supports both the increased level of cAMP and high protein phosphorylation in the basal state [3,7].

Potent restraining mechanisms of this feed-forward signaling axis are required to maintain the basal SANC spontaneous AP firing rate near its mid-range: an increase or reduction in phosphorylation from the basal level by $\beta$-adrenergic or cholinergic receptor stimulation, induces respective increases or decreases in AP firing rate $[1,3,8,9]$. The constitutive activation of ACs in SANC is counterbalanced by constitutive activation of phosphodiesterases (PDEs) (Figure 1), which are enzymes that degrade cAMP and regulate cyclic nucleotide signaling. SANC have a high basal level of PDE activity. For example, a broad-spectrum PDE inhibitor IBMX produces a $\sim$ nine-fold increase in the cAMP level, signifying that PDEs provide negative feedback regulation to limit and fine-tune the basal cAMP level $[5,10,11]$. High basal PDE activity controls not only basal cAMP level but also spatial cAMP distribution within the cell. Rapid degradation of cAMP by PDEs provides functional barriers to CAMP diffusion, and therefore creates discrete intracellular pools of cAMP, functionally and spatially compartmentalizing signaling pathways within the cell $[12,13]$.

An increase in phosphoprotein phosphatase activity is also a potential "brake" on the feed-forward basal phosphorylation-dependent signaling that regulates SANC AP firing (Figure 1). In VM, two major protein phosphatases, PP1 and PP2A, are responsible for $90 \%$ of protein dephosphorylation in the heart [14]. Although they often target the same proteins via Ser ${ }^{16} / \mathrm{Thr}^{17}$ sites, their relative contributions to specific protein substrates is different [15]. PP2A primarily dephosphorylates L-type $\mathrm{Ca}^{2+}$ channels and PP1 primarily dephosphorylates phospholamban (PLB). We have previously demonstrated that basal phosphatase activity in VM regulates protein kinase-dependent phosphorylation of SR $\mathrm{Ca}^{2+}$ cycling proteins, preventing VM sparks to become spontaneous rhythmic LCRs as in SANC [16]. The application of an exogenous phosphoprotein phosphatases (PP) inhibitor, Calyculin A (CyA) [17,18], to rabbit SANC increased the AP firing rate, cyclic AMP level, ATP production, and the AP-induced $\mathrm{Ca}^{2+}$ transient amplitude [18]. In both rabbit SANC and canine Purkinje fibers, CyA also increased $\mathrm{I}_{\mathrm{f}}$ current amplitude $[19,20]$.

However, neither the expression properties and protein levels of specific phosphatases and endogenous phosphatase inhibitors nor the impact of basal phosphatase activity on $\mathrm{Ca}^{2+}$ cycling protein phosphorylation on spontaneous LCRs and other players of the oscillatory coupled-clock system have been studied.

Here, we determined the abundance of RNA transcripts and level of protein expression of PP1 and PP2A in lysates of isolated rabbit SANC. Considering that the catalytic site of PP1 is extremely sensitive to several endogenous inhibitors [21], we also measured the abundance of mRNA transcripts and protein levels of I-1, KEPI and DARPP-32. We also assessed these transcripts in left ventricle cells (LVC) for comparison with their expression abundance in SANC. In intact, freshly isolated SANC, we determined the effects of pharmacological inhibition on phosphorylation of $\mathrm{Ca}^{2+}$ cycling proteins (i.e., PLB) as well as L-type $\mathrm{Ca}^{2+}$ current amplitude, AP parameters, AP-triggered $\mathrm{Ca}^{2+}$ transients, and spontaneous AP firing rates. We also assessed the effects of these inhibitors on spontaneous diastolic LCRs in intact SANC and assessed the effects of purified PP1 and PP2A on LCR characteristics in permeabilized SANC. Finally, we determined whether a numerical model [22], fine-tuned by experimentally observed biophysical effects produced by PP 
inhibition in SANC, could quantitively predict changes in AP firing rate in response to the PP inhibition via a coupled-clock mechanism.

\section{Materials and Methods}

The study was performed in accordance with the Guide for the Care and Use of Laboratory Animals published by the National Institutes of Health (NIH Publication number 85-23, revised 1996). The experimental protocols were approved by the Animal Care and Use Committee of the National Institutes of Health (protocol\#457-LCS-2024). Detailed descriptions of methods are presented in the Online Data Supplement.

\subsection{Isolation of Cardiac Cells}

Single, spontaneously beating SANC and left ventricular cardiomyocytes (LVC) were isolated from the hearts of New Zealand rabbits (Charles River Laboratories, Wilmington, MA, USA) by enzymatic digestion as described previously [11,23].

\subsection{RNA Extraction, $c D N A$ Synthesis, $R T-Q P C R$}

RNA was extracted from isolated rabbit left ventricular (LV), or SANC with RNeasy Mini Kit (Qiagen, Germantown, MD, USA) with DNAse on column digestion according to manufacturer protocol. A total of $2 \mu \mathrm{g}$ of total RNA was used for cDNA preparation in $50 \mu \mathrm{L}$ reaction volume with MMLV reverse transcriptase (Life Technologies, Foster City, CA, USA) using manufacturer recommended conditions with random hexamers for priming. For each synthesis of cDNA, we used no template control for the detection of possible contamination and no RT control for tracing of possible genomic DNA presence.

\subsection{Western Blotting}

For the detection of protein phosphatases and endogenous protein phosphatase inhibitors, cells isolated from rabbit LV and sinoatrial nodes were lysed, transferred to membranes, incubated with antibodies against PPP1CA (Sigma-Aldrich, St. Louis, MO, USA SAB5300221, 1:2500), PPP2CA (Millipore, Bedford, MA, USA 06-222, 1:1000), Inhibitor 1 (Abcam, Cambridge, MA, USA ab40877, 1:10000), KEPI (Biorbyt, Cambridge, UK orb128558, 1:2000), DARPP-32 (Santa Cruz Biotechnology, Dallas, TX, USA sc-271111, 1:1000), or Sarcomeric Alpha-Actinin (Sigma-Aldrich, St. Louis, MO, USA A7811, 1:5000) and developed with Pierce SuperSignal West Pico or West Dura ECL substrate kits (ThermoFisher Scientific, Waltham, MA, USA).

The detection of site specific PLB phosphorylation sites was performed in SANC as previously described [24].

\subsection{Spontaneous APs and $\mathrm{Ca}^{2+}$ Current Recordings in Intact SANC}

A perforated patch-clamp technique was employed to record APs and a ruptured patch-clamp technique was used to record $\mathrm{Ca}^{2+}$ current using an Axopatch-200B patchclamp amplifier (Axon Instruments, Foster City, CA, USA) at $35 \pm 0.5^{\circ} \mathrm{C}$. Only regularly spontaneously beating SANC were chosen for recordings of either APs or currents as described previously $[4,25]$. 
2.5. Confocal Imaging of AP-Induced $\mathrm{Ca}^{2+}$ Transient and Local Subsarcolemmal $\mathrm{Ca}^{2+}$ Releases (LCR) in Intact SANC

AP-induced global $\mathrm{Ca}^{2+}$ transients and spontaneous LCRs were measured in SANC and loaded with a $\mathrm{Ca}^{2+}$ indicator, Fluo-4AM (Thermo Scientific, Waltham, MA, USA) (0.01 $\mathrm{mM}, 15 \mathrm{~min}) 35 \pm 1{ }^{\circ} \mathrm{C}$, via a confocal microscope (Zeiss LSM510, Jena, Germany) in the line-scan mode as described previously [26].

\subsection{SR $\mathrm{Ca}^{2+}$ Content and LCRsin Permeabilized SANC}

A subset of SANC was permeabilized with $0.01 \%$ saponin. After saponin washout, the solution was changed to the recording solution with the addition of $0.03 \mathrm{mM}$ fluo-4 pentapotassium salt (Thermo Scientific, Waltham, MA, USA) and $150 \mathrm{nmol} / \mathrm{L}$ free $\left[\mathrm{Ca}^{2+}\right]_{\mathrm{i}}$. SR $\mathrm{Ca}^{2+}$ content and LCRs were measured with a confocal microscope (Zeiss LSM510, Jena, Germany) in the line-scan mode at $35 \pm 0.5^{\circ} \mathrm{C}$, as previously described [27].

\subsection{Immunolabeling of RyR2 in SANC}

Immunolabeling of RyR2 total and phosphorylated RyR2 at Ser ${ }^{2809}$ were performed in SANC as previously described [28]. Dual confocal images of central sections of SANC were obtained with lasers $633 \mathrm{~nm}$ and $543 \mathrm{~nm}$ via a Zeiss LSM 510 (Carl Zeiss Inc., Jena, Germany).

\subsection{Numerical Modeling}

Numerical model simulations employed a model of rabbit SANC that portrays the pacemaker cell function as a coupled system of a $\mathrm{Ca}^{2+}$-clock, regulated by intracellular $\mathrm{Ca}^{2+}$ cycling and a surface membrane or " $\mathrm{M}$ clock" regulated by the ensemble of surface membrane electrogenic molecules [22].

\subsection{Statistics}

Data are presented as mean \pm SEM. Statistical significance of differences between means was evaluated by Student's $t$-test or analysis of variance (ANOVA) when appropriate. A value of $p<0.05$ was considered statistically significant.

\section{Results}

3.1. Protein Phosphatases and Protein Phosphatase-1 Inhibitor Transcript Abundance and Protein Levels in SANC, RAC and LVC

SANC showed similar profiles of PP1 and PP2A transcript abundance and protein expression (Figure 2A). PP1 transcripts in LVC were equivalent to those in SANC, but PP2A transcript abundance in LVC exceeded that in SANC four-fold (Figure 2A). Whereas I-1 and DARPP-32 transcript abundances were similar in all cell types (Figure 2B), KEPI transcript abundances in LVC exceeded those in SANC (Figure 2B). 
A

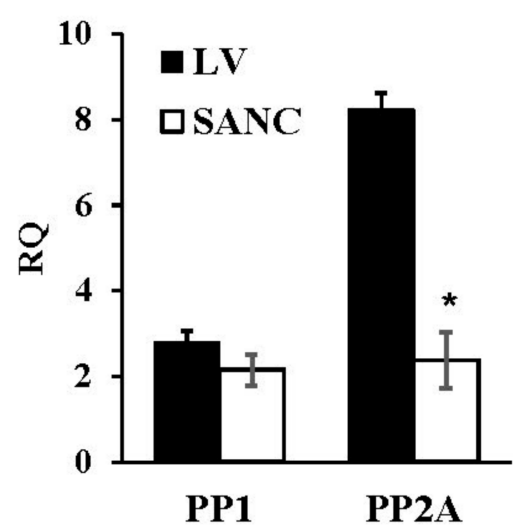

C

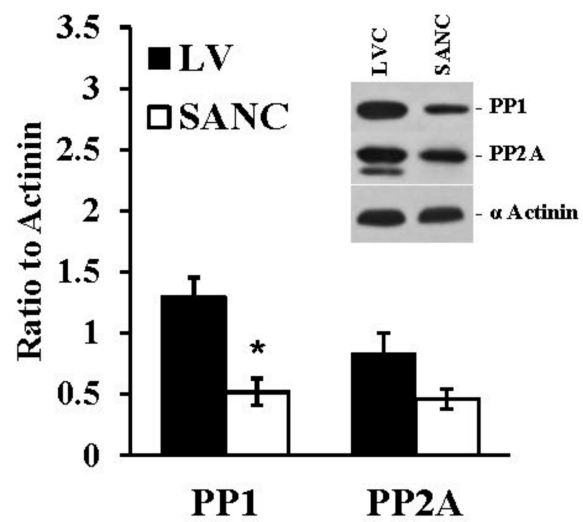

B

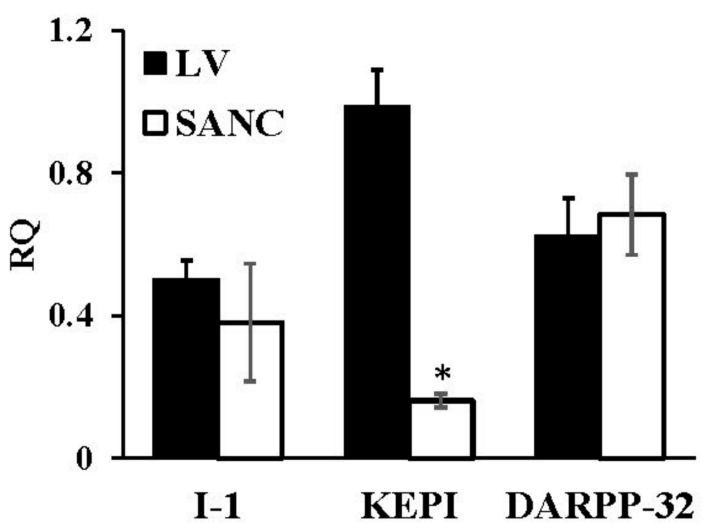

$\mathrm{D}$

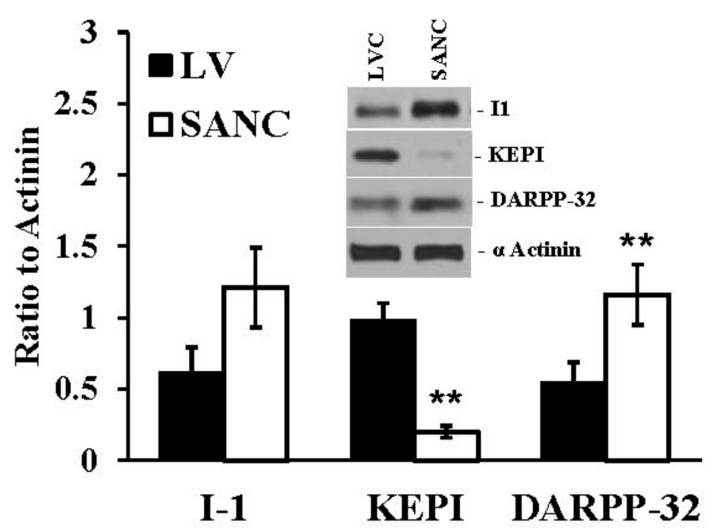

Figure 2. mRNA expression (A,B) and protein abundance (C,D) (Mean+/-SEM) patterns of PP1, PP2A, and PP1 endogenous inhibitors (I-1, KEPI and DARPP-32) normalized to $\beta$-tubulin (mRNA) or $\alpha$-actinin in LVC and SANC ( $n=6$ independent hearts analyzed per group); ${ }^{*} p<0.05,{ }^{* *} p<0.01$ compared to LVC. For alternative transcript names see Table S1. For Primers and probes used for RT-QPCR see Table S2.

PP1 protein levels in LVC exceeded those in SANC; there was also a non-significant trend for LVC PP2A levels to be higher than those in SANC (Figure 2C). The endogenous PP inhibitor I-1(PPI-1) protein levels in SANC tended to be higher than that in LVC (Figure 2D). DARPP-32 levels in SANC also significantly exceeded that in LVC (Figure 2D); in contrast, KEPI protein was markedly reduced in SANC compared to LVC. Thus, compared to LVC, PP1 levels were lower in SANC, while those of endogenous PP1 inhibitors (DARPP-32 and I-1) were higher, a pattern that might be expected, because protein phosphorylation status in SANC is increased compared to that in LVC [27].

\subsection{Effect of PP Inhibition on Target Protein Phosphorylation in SANC}

PLB phosphorylation at PKA-dependent and CaMKII-dependent sites in intact, isolated SANC was assessed prior to and during inhibition of PP by CyA over 1-1000 nmol/L range (Figure 3A,B). 


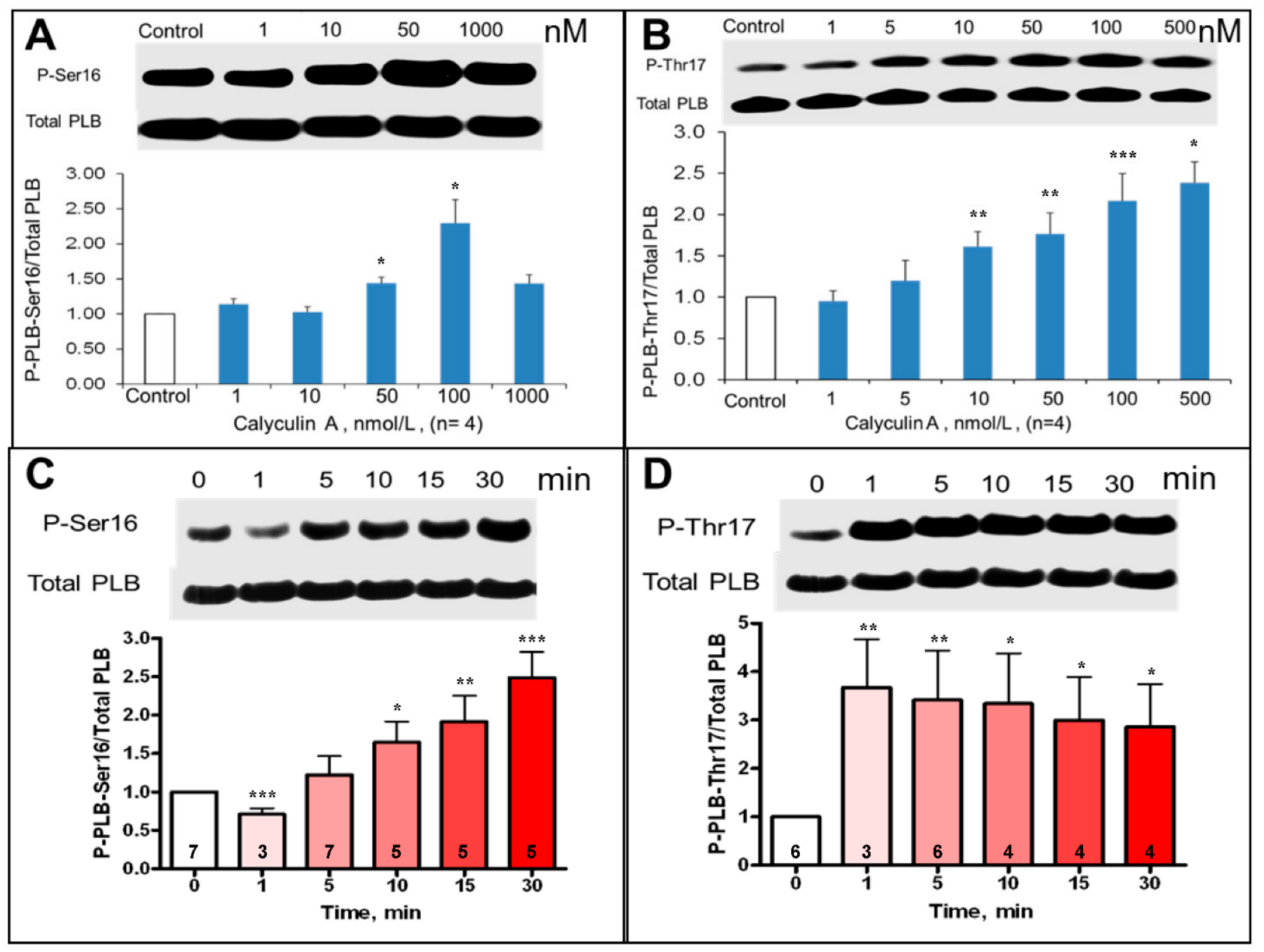

Figure 3. Average effects of CyA on the magnitude of SANC PLB phosphorylation at PKA-dependent Ser ${ }^{16}$ and CaMKIIdependent $\mathrm{Thr}^{17}$ sites. (A,B) Concentration dependence (30 min CyA treatment, $\left.n=4\right)$. (C,D) Rates of phosphorylation in response to $100 \mathrm{nmol} / \mathrm{L}$ CyA. Representative Western blots of phosphorylated PLB and total PLB are presented in the upper part of each panel. Number of samples is shown in each column. ${ }^{*} p<0.05,{ }^{* *} p<0.01,{ }^{* *} p<0.001$ vs. control.

CyA induced a significant, 2.5-3-fold concentration-dependent increase in PLB phosphorylation at both PKA-dependent Ser $^{16}$ and CaMKII-dependent $\mathrm{Thr}^{17}$ sites (Figure 3A,B). Interestingly, the increase in PLB phosphorylation at $\mathrm{Thr}^{17}$ in response to $100 \mathrm{nmol} / \mathrm{L} \mathrm{CyA}$ was rapid and complete within one minute (Figure 3D), while PLB phosphorylation at Ser ${ }^{16}$ increased gradually and reached its peak over $30 \mathrm{~min}$ (Figure 3C). Inhibition of PP activity by CyA in intact SANC also significantly increased phosphorylation of RyR at $\mathrm{Ser}^{2809}$ sites (Figure S1), which were phosphorylated by both PKA and CaMKII [2].

\subsection{Effects of PP Inhibition by CyA or Purified PP1 and PP2A on LCRs in Permeabilized SANC}

To determine the direct effects of $\mathrm{PP}$ on $\mathrm{Ca}^{2+}$ clock functions without interference of ion channels (e.g., L-type $\mathrm{Ca}^{2+}$ channels), we applied CyA to saponin-permeabilized SANC (Figure 4). CyA increased the peak of rhythmic LCR frequency as assessed by Fast Fourier transform analysis (FFT) and shifted it to a higher frequency from $2.10 \mathrm{~Hz}$ to $2.57 \mathrm{~Hz}$ in the example in Panel C and by $50 \%$ on average from $2.2 \pm 0.2$ to $3.2 \pm 0.4 \mathrm{~Hz}(n=4)$. 

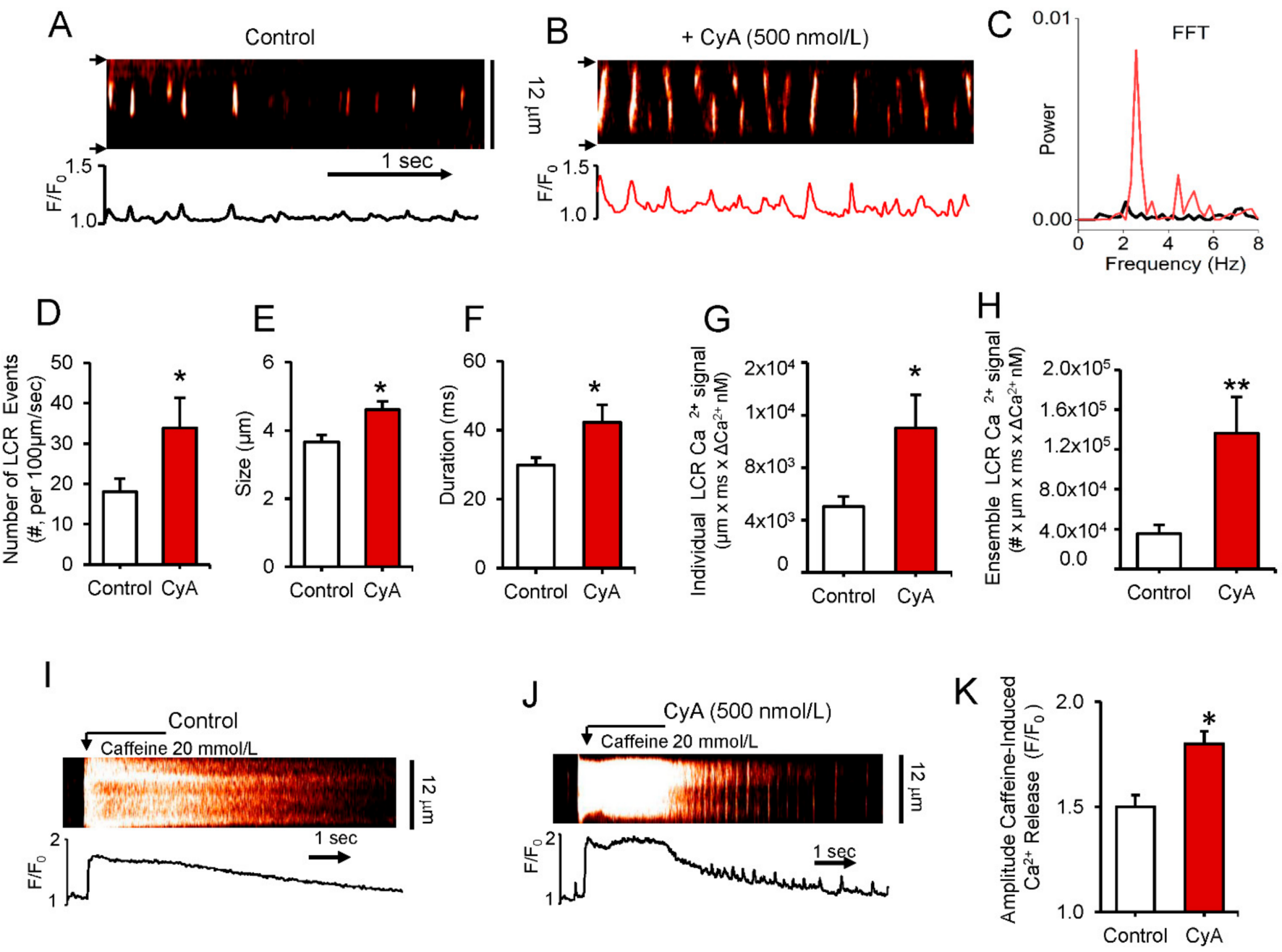

Figure 4. (A,B) Representative confocal line-scan images and (C) a fast Fourier transform (FFT) of $\mathrm{Ca}^{2+}$ oscillations in a permeabilized SANC bathed in $150 \mathrm{nmol} / \mathrm{L}\left[\mathrm{Ca}^{2+}\right]$ in control conditions and during superfusion with $500 \mathrm{nmol} / \mathrm{L} \mathrm{CyA}$. (D-H) Average changes in local $\mathrm{Ca}^{2+}$ release characteristics (LCRs) in control and during superfusion with $500 \mathrm{nmol} / \mathrm{L}$ CyA $(n=6)$ : (D) Number of LCR events per $100 \mu \mathrm{m}$ of the line-scan image and during a 1-sec time interval; (E) LCR size (as FWHM, the full width at half-maximum amplitude); (F) LCR duration (as FDHM, the full duration at half-maximum amplitude); (G) $\mathrm{Ca}^{2+}$ signals of Individual LCRs ( $\mu$ mxmsx $\Delta \mathrm{Ca}^{2+} \mathrm{nmol} / \mathrm{L}$ ); (H) $\mathrm{Ca}^{2+}$ signals of the LCR ensemble (the integrated $\mathrm{Ca}^{2+}$ signal of all LCRs), ${ }^{*} p<0.05,{ }^{* *} p<0.01$ paired $t$-test vs control, $n=6$. Representative confocal images $(\mathbf{I}, \mathbf{J})$ and the average amplitude of the $\mathrm{SR} \mathrm{Ca}^{2+}$ release $(\mathbf{K})$ induced by a rapid spritz application of $20 \mathrm{mM}$ caffeine in permeabilized SANC during $500 \mathrm{nmol} / \mathrm{L} \mathrm{CyA} \mathrm{superfusion}(n=12)$ and in control $(n=7)$. ${ }^{*}<0.05$, 2-tailed $t$-test.

The average effects of CyA on LCR characteristics in permeabilized SANC are illustrated in Figure 4 (Panels D to H). CyA increases average LCR frequency by more than $80 \%$ (Panel D), average LCR size by 26\% (Panel E) and LCR duration by $42 \%$ (Panel F). The mean $\mathrm{Ca}^{2+}$ signal of individual LCRs increases 2.2-fold (Panel G), and CyA increased the mean ensemble LCR $\mathrm{Ca}^{2+}$ signal about four-fold (Panel H). To determine whether an increase in the ensemble LCR Ca ${ }^{2+}$ signal is associated with an increase in the SR $\mathrm{Ca}^{2+}$ load in permeabilized SANC, we applied a pulse of caffeine, which rapidly empties the SR $\mathrm{Ca}^{2+}$ store before and after CyA application (Figure 4I,J). On average CyA induced a 20\% increase in the mean amplitude of the caffeine-induced $\mathrm{Ca}^{2+}$ transients (Figure $4 \mathrm{~K}$ ). Thus, a $20 \%$ increase in the caffeine-induced SR $\mathrm{Ca}^{2+}$ release was accompanied by a four-fold increase in the ensemble of LCR Ca ${ }^{2+}$ signal, suggesting an increase in kinetics of SR $\mathrm{Ca}^{2+}$ cycling in response to PP1 inhibition by CyA. This idea is consistent with the effects of CyA on PLB and RyR phosphorylation (Figure 3 and Figure S1, respectively). In contrast 
to CyA, superfusion of permeabilized SANC with okadaic acid produced no changes in LCR characteristics (Figure S2).

Figure 5 shows the effects of direct application of PP1 or PP2A enzymes to permeabilized SANC. While application of PP1 markedly suppressed LCR number, amplitude and size and decreased ensemble of LCR $\mathrm{Ca}^{2+}$ signal by $~ 7.4$-fold, there were no changes in LCR characteristics in response to PP2A application (Figure 5). The lack of an effect of purified PP2A on LCRs in permeabilized SANC indicates that PP1 activity but not PP2 activity suppresses spontaneous SR $\mathrm{Ca}^{2+}$ cycling of SANC.
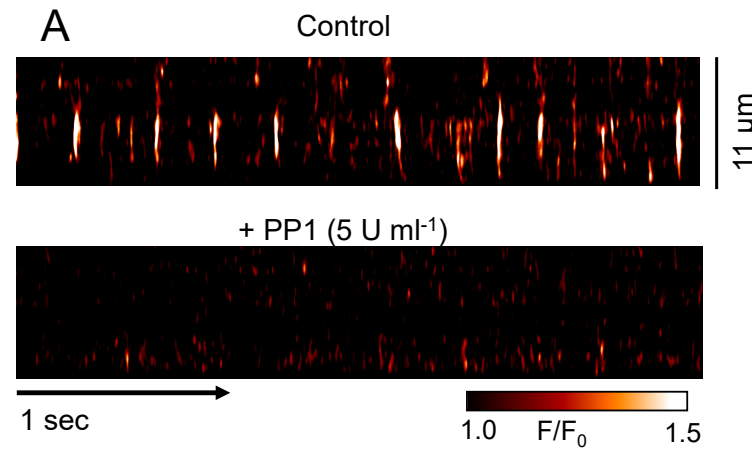

B

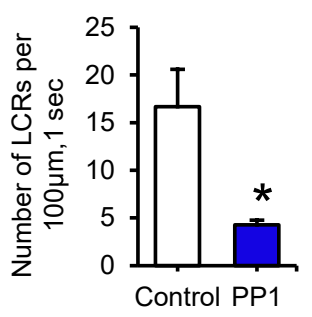

$\mathrm{D}$

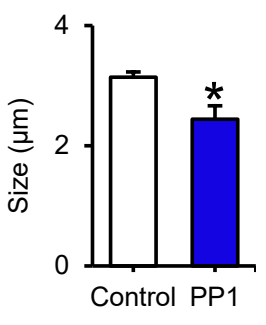

C

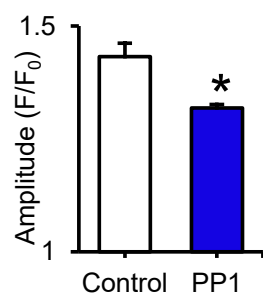

\section{E}

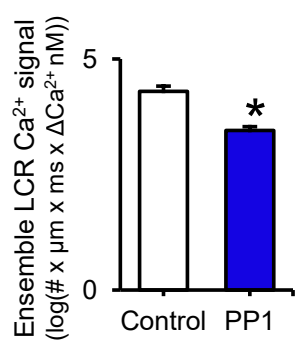

F

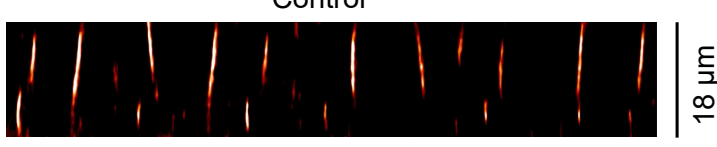

+ PP2A (5 U ml-1) (2 min)

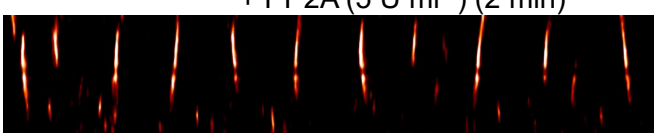

+ PP2A (5 U ml-1) (4 min)
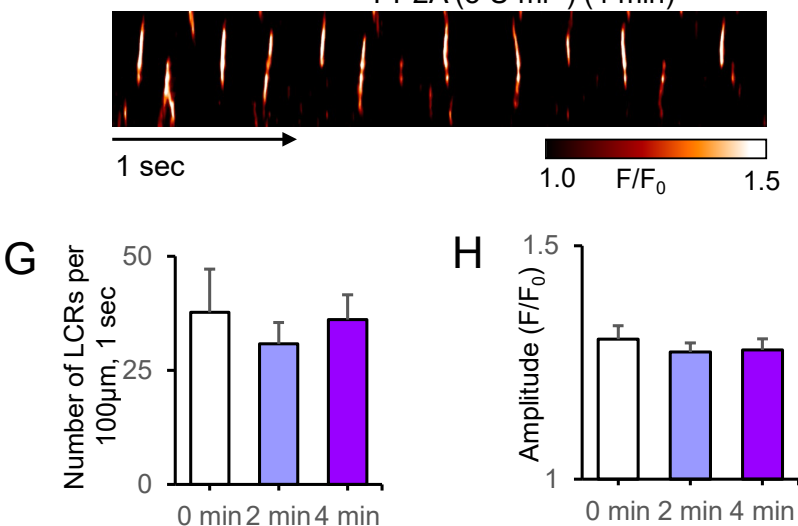

$\mathrm{H}$

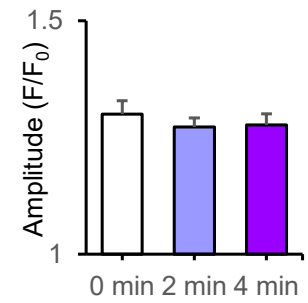

I

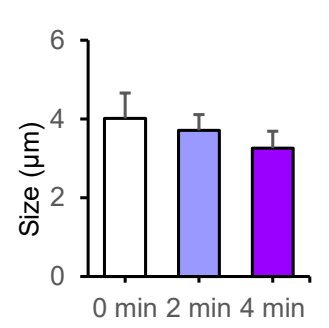

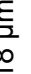


the firing rate in rabbit SANC. We observed that CyA levels as low as $100 \mathrm{nM}$ significantly increased the spontaneous AP firing rate in SANC by $25 \%$ (Figure 6). The average effects of PP inhibition by CyA on AP parameters are listed in Table S3. The increase in the diastolic depolarization rate (DD slope) was accompanied by a decrease in the spontaneous SANC cycle length (SANC cycle), a decrease in the AP duration at 75\% (APD75), a decrease in the time to the onset of non-linear diastolic depolarization (TNLDD, see methods), and an increase in the SANC firing rate at all CyA concentrations (100-500 nmol/L).

A Control Calyculin A

Washout
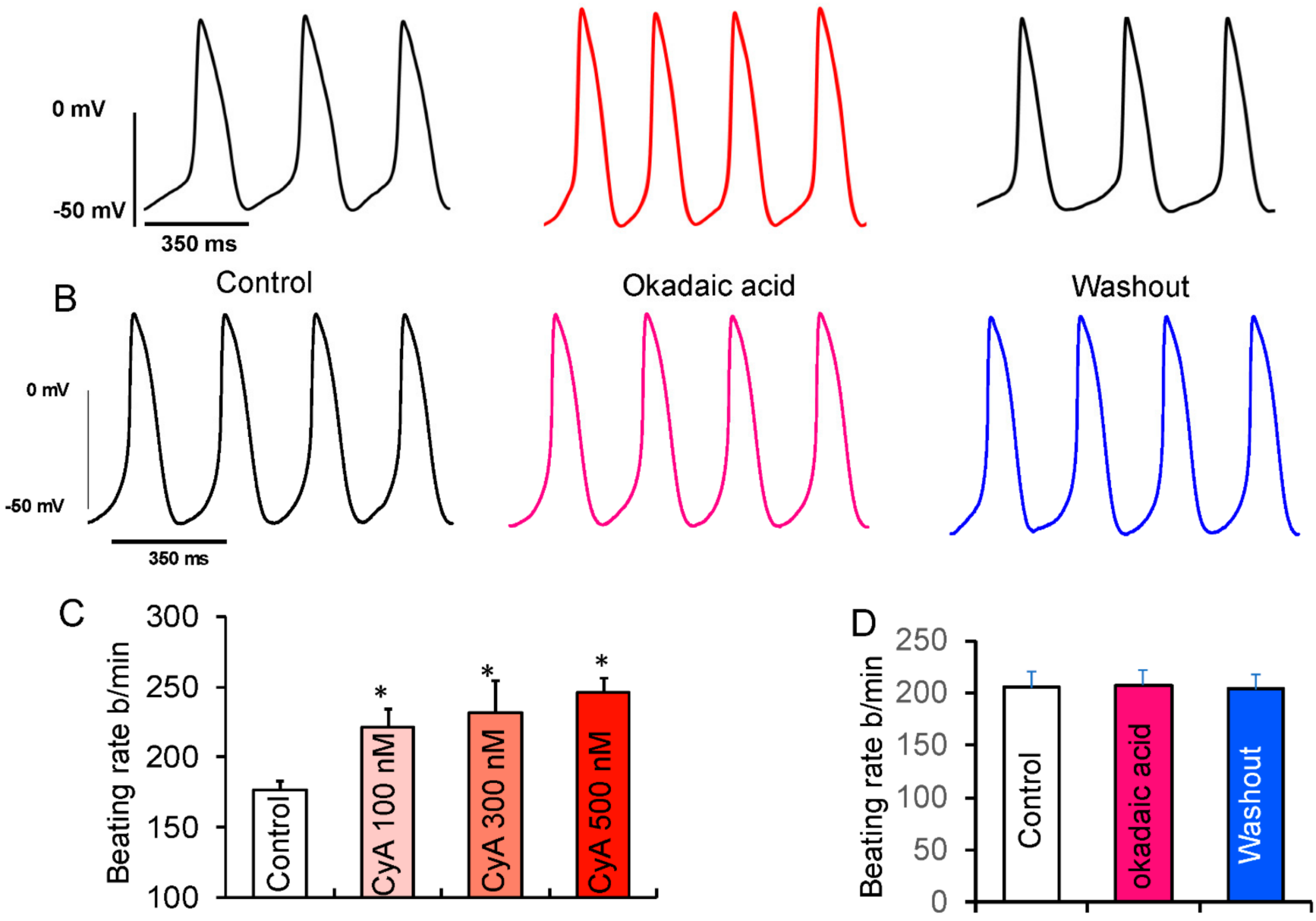

Figure 6. Effects of suppression of PP activity by CyA or OKA on spontaneous beating of isolated rabbit SANC. (A) Representative example of APs recorded in SANC before and during superfusion with $100 \mathrm{nmol} / \mathrm{L}$ CyA and following washout of CyA. (B) Representative example of SANC APs recorded prior to and during superfusion with $100 \mathrm{nmol} / \mathrm{L}$ OKA and after OKA washout. (C) The average increase in the spontaneous AP firing rate did not significantly differ in response to $100(n=10), 300(n=5)$ or $500 \mathrm{nmol} / \mathrm{L}(n=6)$ of CyA. (D) Average spontaneous AP firing rate responses to OKA $(n=6)$. * $p<0.05$ vs. control.

To distinguish whether these effects of CyA (Figure 6) were mediated via inhibition of PP1, PP2A, or both, we performed additional experiments employing a selective PP2A inhibitor okadaic acid (100 nmol/L). Okadaic acid also inhibits PP1, but with a 100-fold lower potency. It was shown that when applied to living cells at $100 \mathrm{nmol} / \mathrm{L}$ concentration, it does not inhibit PP1 [29]. Several studies have successfully used a $100 \mathrm{nmol} / \mathrm{L}$ concentration of okadaic acid to investigate the role of PP2A in VM $[30,31]$.

In contrast to the effect of $\mathrm{CyA}$, there was no increase in the spontaneous $\mathrm{AP}$ firing rate after inhibition of PP2A by okadaic acid (Figure 6B,D), suggesting that the observed 
effects of CyA on the basal AP firing rate were largely mediated by the inhibition of PP1, consistent with the lack of effects of purified PP2A on LCR characteristics (Figure 5).

\subsection{Effect of PP Inhibition on $\mathrm{Ca}^{2+}$ Release during AP Firing Rate in Intact SANC}

Figure 7 shows representative confocal line-scan images of a fluo-4 loaded spontaneous $\mathrm{AP}$ firing SANC prior to and during exposure to $\mathrm{CyA}$. The increase in $\mathrm{AP}$ firing rate induced by $100 \mathrm{nmol} / \mathrm{L}$ CyA (Figure 7A) was accompanied by an acceleration in the decay of APinduced $\mathrm{Ca}^{2+}$ transient indicated by the reduction in the duration of the $\mathrm{Ca}^{2+}$ transient amplitude at $50 \%\left(\mathrm{~T}_{50}\right.$ : from $104.6 \pm 7.2$ to $\left.86.7 \pm 5.4 \mathrm{~ms}, p<0.05, n=12 \mathrm{SANC}\right)$ and at $90 \%$ ( $\mathrm{T}_{90}$ : from $206.2 \pm 16.5$ to $164.5 \pm 11.1 \mathrm{~ms}, p<0.003, n=12 \mathrm{SANC}$ ). This effect is consistent with an increase in $\mathrm{SR} \mathrm{Ca}^{2+}$ pumping rate that is expected to occur concurrently with CyA effects to increase PLB phosphorylation (Figure 3).

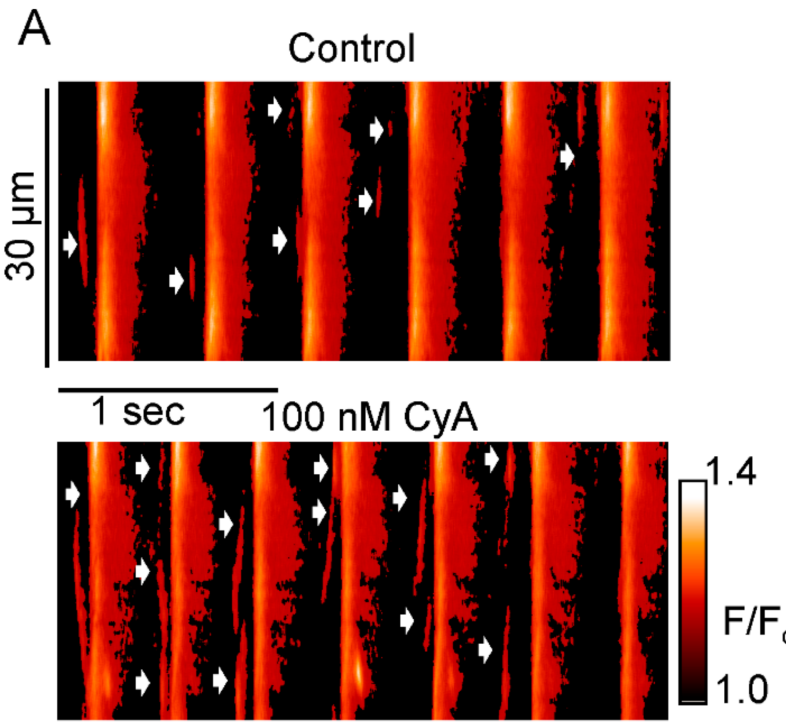

B

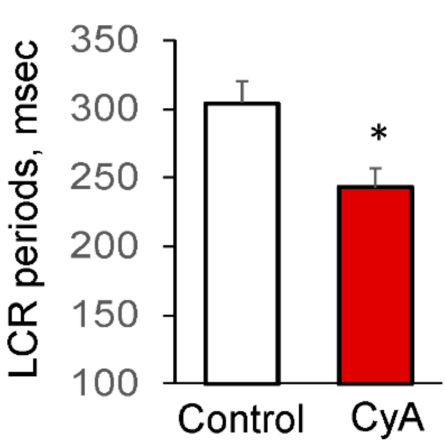

$\mathrm{E}$

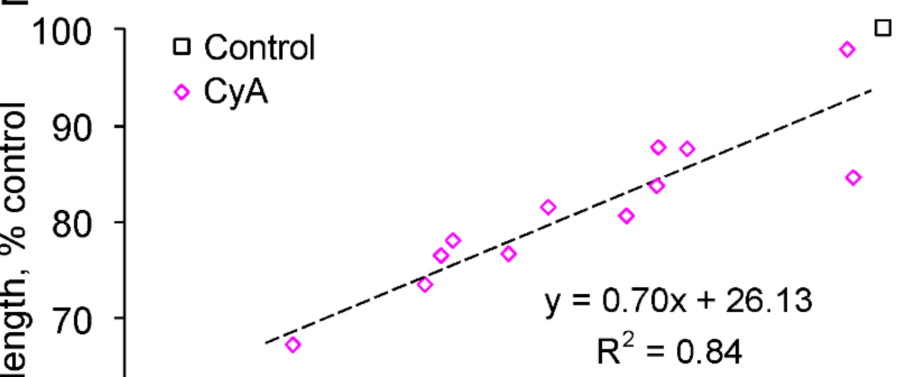

50

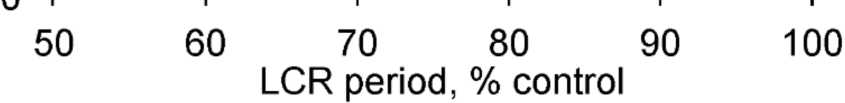

D

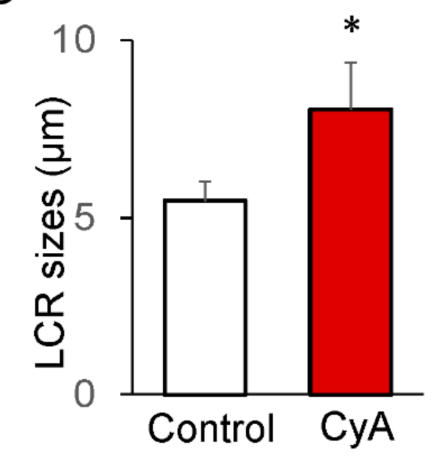

Figure 7. PP inhibition by CyA increases the LCR number and size of LCRs in SANC during spontaneous AP firing. (A) Confocal line-scan image of a representative SANC prior to and during exposure to 100 nmol/L CyA; CyA-induced changes in: (B) LCR period; (C) LCR number per cycle; (D) LCR size $(n=12)$. (E) PP inhibition-induced changes in the LCR periods predict the concurrent changes in the AP cycle lengths $(n=12) .{ }^{*} p<0.05$ vs. control.

PP inhibition in spontaneously beating SANC significantly increased the LCR size by $\sim 50 \%$ and number of LCRs per spontaneous cycle by $\sim 20 \%$, while reducing the LCR period by about $20 \%$. The reduction in the LCR periods was accompanied by a decrease in the spontaneous SANC cycle lengths, and there was a close correlation between these parameters $\left(R^{2}=0.84\right.$, Figure $\left.7 E\right)$. 


\subsection{Effect of PP Inhibition by CyA on L-Type $\mathrm{Ca}^{2+}$ Current in Intact Voltage-Clamped SANC}

$\mathrm{Ca}^{2+}$ influx via L-type $\mathrm{Ca}^{2+}$ current is a crucial component of $\mathrm{Ca}^{2+}$ cycling that sustains LCR activity in intact SANC [32], and L-type $\mathrm{Ca}^{2+}$ channels are likely targets of PP [30]. Figure 8 shows that PP inhibition by CyA augments the amplitude of $\mathrm{I}_{\mathrm{CaL}}$ by about $30 \%$ and shifts its I-V relationship by $\sim 10 \mathrm{mV}$ leftward $(n=9)$. This result is consistent with a suppression of basal-state $\mathrm{Ca}^{2+}$ influx via L-type $\mathrm{Ca}^{2+}$ channels by basal phosphatase activity.

A

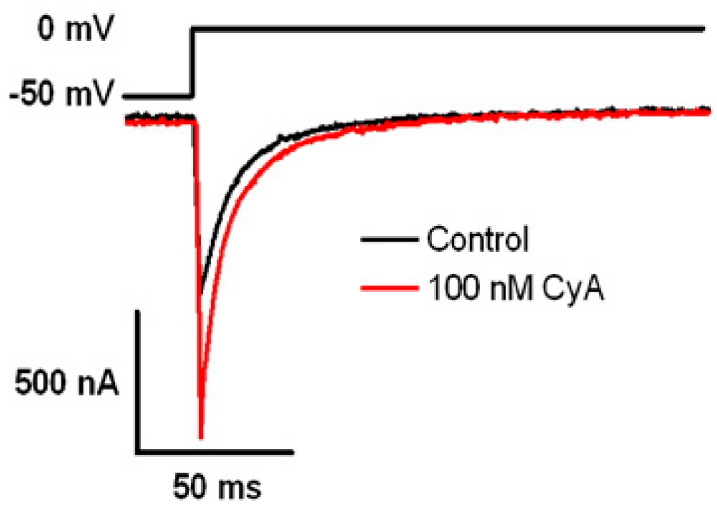

B

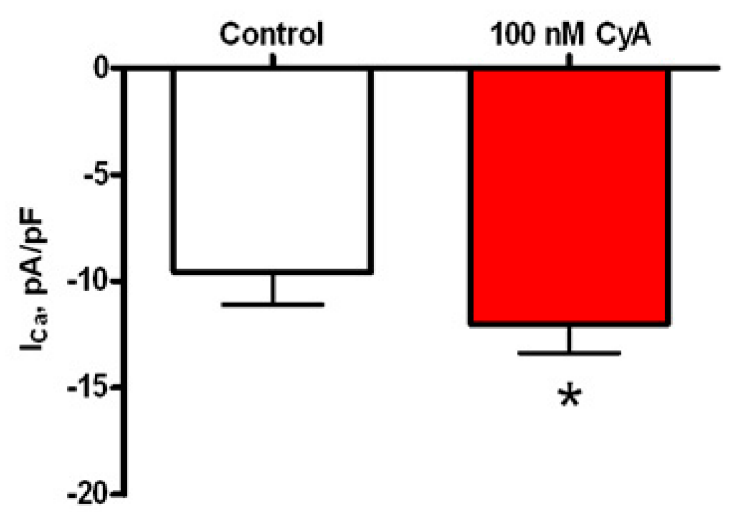

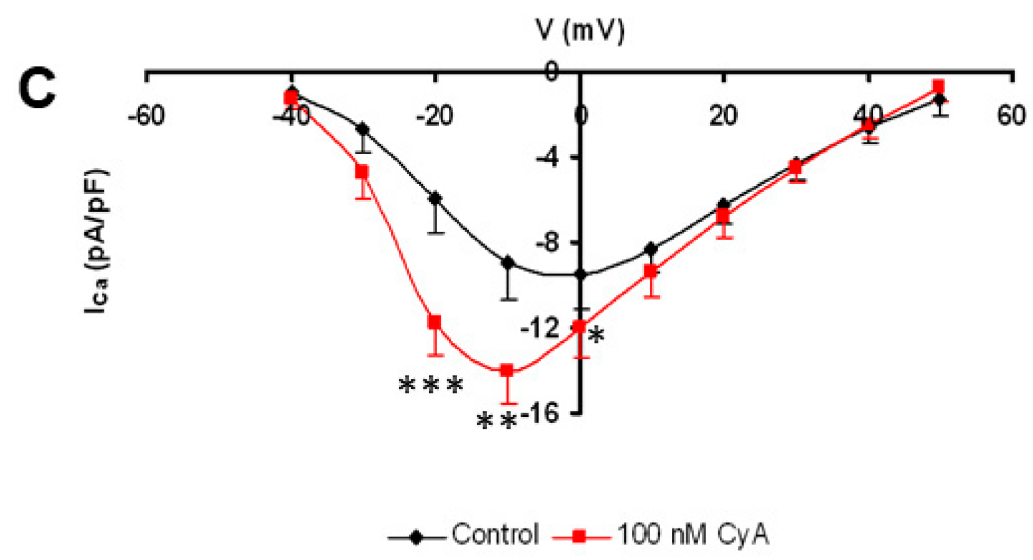

Figure 8. PP inhibition-induced potentiation of L-type $\mathrm{Ca}^{2+}$ current amplitude. (A) The voltage clamp protocol and representative original L-type $\mathrm{Ca}^{2+}$ current recordings prior to and during PP inhibition by CyA. Average effects of CyA on the amplitude (B) and current-voltage relationship (C) of $\mathrm{I}_{\mathrm{Ca}}$ in SANC $(n=9)$. L-type Ca ${ }^{2+}$ current amplitudes were normalized to membrane capacitance. ${ }^{*} p<0.05,{ }^{* *} p<0.01,{ }^{* * *} p<0.001$.

\subsection{Numerical Modeling of the Effect of PP Inhibition by CyA in SANC}

We numerically simulated the biophysical effects of PP inhibition by $100 \mathrm{nM}$ CyA in SANC (Figure 9). The quantitative impacts of increased protein phosphorylation on the diastolic LCRs' release characteristics and spontaneous beating rate were explored by simultaneously increasing the maximum SR Ca ${ }^{2+}$ pumping rate $\left(\mathrm{P}_{\mathrm{up}}\right)$, mimicking the effect of PLB phosphorylation, and by increasing the maximum conductance of $\mathrm{I}_{\mathrm{CaL}}\left(\mathrm{g}_{\mathrm{CaL}}\right)$. 

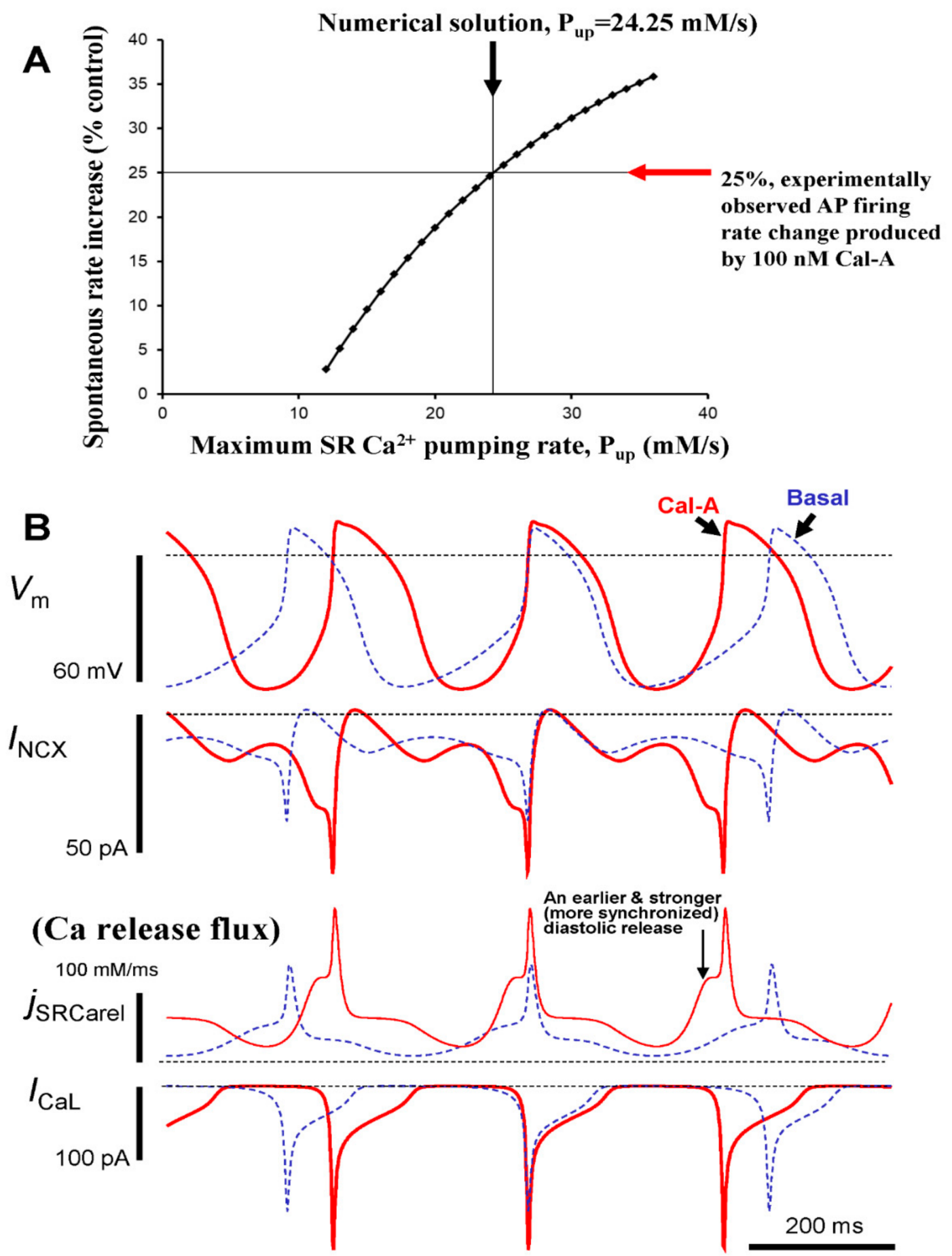

Figure 9. Numerical model simulations of the experimentally defined effects of protein phosphatase inhibition by CyA on spontaneous AP firing rate of rabbit SANC. (A) A numerical solution in which the maximum SR Ca ${ }^{2+}$ pumping rate, $\mathrm{P}_{\mathrm{up}}$ was increased to $24.25 \mathrm{mM} / \mathrm{s}$, reproduced the experimentally observed increase in AP firing rate by $25 \%$ in the presence of $100 \mathrm{nM}$ of CyA. (B) Simulations of the membrane potential $\left(\mathrm{V}_{\mathrm{m}}\right)$, NCX current $\left(\mathrm{I}_{\mathrm{NCX}}\right), \mathrm{L}$-type Ca ${ }^{2+}$ current $\left(\mathrm{I}_{\mathrm{CaL}}\right)$, and Ca ${ }^{2+}$ release flux (jsRCarel) before (dashed line) and during CyA application (CyA, solid line).

In accordance with our experimental results, the purpose of our numerical modeling was to combine the effects of $\mathrm{I}_{\mathrm{CaL}}$ and PLB phosphorylation in a biophysical detailed model to ascertain whether these effects can explain the PP firing rate change observed experimentally during PP inhibition. Because our experimental data showed that the maximum peak $\mathrm{I}_{\mathrm{CaL}}$ is increased by $100 \mathrm{nmol} / \mathrm{L} \mathrm{CyA}$, on average from 9.6 to $14.2 \mathrm{pA} / \mathrm{pF}$ (Figure 8), $\mathrm{g}_{\mathrm{CaL}}$ was increased in the model by $47.9 \%$ (Figure 9). Because PLB phosphorylation 
substantially increases ( $>2$ fold vs. control, Figure 3), CyA surely increases $P_{\text {up }}$. This magnitude of PLB phosphorylation increase is, indeed, very large, actually close to an extreme change, and comparable to that (also 2.5 times) reported for the maximum effect of PDE inhibition by isobutylmethylxanthine (IBMX) in rabbit SANC [11]. The specific changes of $P_{\text {up }}$ in intact SANC that result from increases in PLB phosphorylation, however, are unknown and cannot be assessed experimentally during spontaneous AP firing. Therefore, we explored model predictions when $\mathrm{P}_{\text {up }}$ was gradually increased whereas $\mathrm{g}_{\mathrm{CaL}}$ was instantly increased, (by $47.9 \%$, from 0.46 to $0.69 \mathrm{nS} / \mathrm{pF}$, see above). This parameter sensitivity analysis allowed us to determine whether a numerical solution for the experimentally observed chronotropic effect of CyA to increase AP firing rate by $25 \%$ could be found with a reasonable $\mathrm{P}_{\text {up }}$ increase (i.e., within reported PLB modulatory capacity on $\mathrm{P}_{\mathrm{up}}$ ). A numerical solution for the experimental effect of CyA increasing the AP firing rate by $25 \%$ was indeed identified in response to an approximate doubling of $P_{\text {up }}$ in the model from 12 to $24.25 \mathrm{mM} / \mathrm{s}$ (Figure 9A). Of note, the CyA-induced increase in $\mathrm{g}_{\mathrm{CaL}}$ alone (i.e., without a $\mathrm{P}_{\text {up }}$ increase) results only in a small change in the $\mathrm{AP}$ firing rate $(2.8 \%)$, i.e., insufficient to account for the experimentally observed rate change of $25 \%$.

To gain further insight into the biophysical mechanism of the AP firing rate increase caused by PP inhibition in response to CyA, the kinetics of key components of the system were numerically simulated (Figure $9 \mathrm{~B}$ ), including $\mathrm{I}_{\mathrm{NCX}}, \mathrm{I}_{\mathrm{CaL}}$, and diastolic $\mathrm{SR} \mathrm{Ca}{ }^{2+}$ flux. Model simulations predicted that PP inhibition resulted in earlier and stronger diastolic $\mathrm{Ca}^{2+}$ release flux, consistent with the experimental observation of a concurrent reduction in LCR period and increase in LCR amplitude (Figures 4 and 7). The earlier and stronger diastolic $\mathrm{Ca}^{2+}$ release, in turn, activated, an earlier and stronger $\mathrm{I}_{\mathrm{NCX}}$ (Figure 8B) that accelerated diastolic depolarization and the activation of $\mathrm{I}_{\mathrm{CaL}}$.

Our immunolabeling results indicated that Ser2809 phosphorylation normalized to total RyR increased by $38.5 \%$ by CyA (from 1.3 to 1.8, Figure S1). Because this site is known to be phosphorylated by both PKA and CaMKII, it was uncertain how this increase in phosphorylated RyR translates into the $\mathrm{Ca}^{2+}$ release formulation in the model. To specifically address this issue, we performed an additional parametric sensitivity analysis to determine the robustness of our simulation results for $\mathrm{CyA}$ with respect to this increase in RyR phosphorylation. In the basal state model simulation, RyR opening rate $\left(\mathrm{k}_{\mathrm{s}}\right)$ was set to $250 \mu^{-1}$. In our sensitivity analysis, $\mathrm{k}_{\mathrm{s}}$ varied over a wide range, from $100 \mu \mathrm{s}^{-1}$ (which is substantially below basal RyR opening rate) to $400 \mu^{-1}$ (which is substantially above basal RyR opening rate) in increments of $10 \mu^{-1}$ (total 31 models were tested). The model simulations showed that changes in the RyR opening rate over this broad range of ks applied on top of $\mathrm{g}_{\mathrm{CaL}}$ and $\mathrm{P}_{\text {up }}$ increases (Figure 9, marked by arrows for $25 \%$ rate increase) did not substantially affect the $25 \%$ AP firing rate increase generated by $\mathrm{g}_{\mathrm{CaL}}$ and $\mathrm{P}_{\text {up }}$ alone (Figure $\mathrm{S} 3$ ).

Because $\mathrm{I}_{\mathrm{f}}$ was not measured experimentally in our study, we also performed a parametric sensitivity analysis of our numerical model to test whether our simulation of CyA effects was robust with respect to possible changes in $\mathrm{I}_{\mathrm{f}}$. A classical study [33] showed that cAMP can shift $\mathrm{I}_{\mathrm{f}}$ activation by up to $7.8 \mathrm{mV}$ to more depolarized potential. Thus, we also shifted the respective model parameter $\mathrm{V}_{\mathrm{If}, 1 / 2}$ (the half maximum activation voltage of $\mathrm{I}_{\mathrm{f}}$ ) by $7.8 \mathrm{mV}$, i.e., from $-64 \mathrm{mV}$ to $-56.2 \mathrm{mV}$. Our simulations, however, revealed that the AP firing rate remained essentially unchanged (within 1\%) when this increase in sensitivity to hyperpolarization of $\mathrm{I}_{\mathrm{f}}$ was applied on top of $\mathrm{I}_{\mathrm{CaL}}$ and $\mathrm{P}_{\text {up }}$ increases (Figure 9 , marked by arrows for $25 \%$ rate increase). On the other hand, it was also suggested [19] that CyA modulates $\mathrm{I}_{\mathrm{f}}$ in a different way, i.e., not by shifting $\mathrm{V}_{\mathrm{If}, 1 / 2}$ but by increasing the maximum $\mathrm{I}_{\mathrm{f}}$ conductance by $39.6 \%$. We also tested this mechanism by increasing the maximum $\mathrm{I}_{\mathrm{f}}$ conductance ( $\mathrm{g}_{\mathrm{h}}$ parameter) in our model by $39.6 \%$ from 0.4 to $0.5584 \mathrm{nS} / \mathrm{pF}$. This simulation also revealed only a minor increase (within 1\%) in the AP firing rate. Thus, our simulations showed that neither the shift in $\mathrm{V}_{\mathrm{If}, 1 / 2}$ nor a major increase in $\mathrm{I}_{\mathrm{f}}$ conductance influenced our result of a $25 \%$ rate increase by CyA application (Figure $9 \mathrm{~A}$ ). 


\section{Discussion}

4.1. Basal PP1 Activity Modulates a Coupled-Clock System That Drives Spontaneous Automaticity of SANC

Basal protein phosphorylation in SANC is enabled by $\mathrm{Ca}^{2+}$-calmodulin activated adenylyl cyclases type 1 and 8 , and CaMKII $[2-4,7]$. Phosphorylation of intracellular $\mathrm{Ca}^{2+}$ cycling proteins $\left(\mathrm{Ca}^{2+}\right.$ clock) and surface membrane electrogenic proteins (membrane clock) at PKA and CAMKII-dependent sites in SANC are required for normal operation of a dynamic coupled-clock system that determines the spontaneous basal-state AP firing rate [3] and its AP in response to $G$ protein coupled receptor stimulation [1]. The present results show that the effects of PP1 inhibition to increase AP firing rate result from integrated changes in functions of sarcolemmal ("M clock") and intracellular (" $\mathrm{Ca}^{2+}$ clock") proteins, including amplification of L-type $\mathrm{Ca}^{2+}$ current amplitude, leading to increases in $\mathrm{Ca}^{2+}$ influx and $\mathrm{SR} \mathrm{Ca}^{2+}$ load, accompanied by changes in LCR characteristics. CyA-induced increase of the SANC AP firing rate in our study resulted from inhibition of PP1 because inhibition of PP2A by okadaic acid had no effect on the AP firing rate of intact SANC (Figure 6) or on LCR characteristics in permeabilized SANC (Figure S2). Further, exposure of permeabilized SANC to purified PP2A enzyme had no effect on LCRs, in contrast to a marked effect on LCR characteristics induced by PP1 enzyme in permeabilized SANC (Figure 5) or by CyA in intact SANC (Figure 7). The PP inhibition induced an increase in the kinetics of $\mathrm{SR} \mathrm{Ca}^{2+}$ cycling, which resulted, in part at least, from increased PLB phosphorylation, (Figure 3) leading to an increased rate of $\mathrm{Ca}^{2+}$ pumping into SR, manifested in intact, spontaneously firing SANC as an increase in the kinetics of the decay rate of the AP-induced $\mathrm{Ca}^{2+}$ transient.

\subsection{PP Transcript and Endogenous PP Inhibitor $m R N A$, and Protein Expression in SANC}

It has been previously documented that basal phosphorylation levels of PLB and RyR are substantially lower in LVC than in SANC [3]. The present results (Figure 2) demonstrate that PP1 protein level and PP2A transcript abundance are both substantially higher in LVC than in SANC. This may explain, in part, why basal phosphorylation of $\mathrm{Ca}^{2+}$ cycling proteins in LVC is suppressed compared to that in SANC. PP1 is the major phosphatase that dephosphorylates PLB in LVC [34]. Immunolabeling of PP1 endogenous phosphatase inhibitors I-1 and DARPP-32 proteins were approximately two-fold greater in SANC than in LVC (Figure 2C,D), and KEPI was about four-fold lower in SANC than in LVC (Figure 2D). These cell type differences appear to be due to differences in protein degradation because mRNA transcripts for I-1, DARPP-32 do not differ between SANC and LVC. In contrast, the reduced level of KEPI in SANC can be attributed to reduced KEPI transcripts, which are lower compared to those in LVC. Of note, in the context of reduced I-1 and DARPP-32 immunolabeling, PP1 protein immunolabeling in LVC exceeded that in SANC. It is important to note that other PP isoforms are expressed in SANC [35] but not assessed in the present study.

\subsection{Phosphatase-Dependent Regulation of $\mathrm{Ca}^{2+}$ Clock Proteins}

In the present study, PLB phosphorylation in SANC increased by about 2-3-fold in response to PP inhibition by CyA (Figure 3). An unexpected but rather interesting finding of our study was that following exposure to CyA, CaMKII-dependent phosphorylation of PLB at Thr ${ }^{17}$ increases rapidly, whereas at Ser ${ }^{16}$, the PKA-dependent site, the increase in phosphorylation occurs gradually (Figure 3 ). This result might indicate that PP activity within SANC is involved in temporal coordination of PKA and CaMKII-dependent phosphorylation.

Our results in permeabilized SANC indicate that PP inhibition by CyA induces a 20\% increase in $\mathrm{SR} \mathrm{Ca}^{2+}$ loading, resulting in a marked increase in the kinetics of $\mathrm{Ca}^{2+}$ cycling, as evidenced by a fourfold increase in total spontaneous $\mathrm{Ca}^{2+}$ release (the ensemble of LCR $\mathrm{Ca}^{2+}$ signal (Figure 4) per unit time). Thus, the effects on SR $\mathrm{Ca}^{2+}$ cycling suggest that $\mathrm{PP}$ inhibition not only increases $\mathrm{Ca}^{2+}$ pumping into SR but also accelerates the kinetics 
of the restitution phase between $\mathrm{Ca}^{2+}$ pumping and $\mathrm{Ca}^{2+}$ release and synchronization of the phases of spontaneous LCRs throughout the cell, reflecting increased availability of RyRs to become spontaneously activated. Rhythmicity of spontaneous diastolic LCRs in SANC appear to emerge from effects resulting from PKA and CaMKII-dependent protein phosphorylation, because when either PKA or CaMKII are inhibited, LCRs become small and irregular and generate a markedly suppressed ensemble $\mathrm{Ca}^{2+}$ signal, resembling $\mathrm{Ca}^{2+}$ sparks in VM [27], LCR occurrence is no longer rhythmic, but becomes stochastic. Indeed, following an increase in the SR Ca ${ }^{2+}$ cycling protein, phosphorylation in the presence of PDE and PP inhibition, rhythmic LCRs emerge in permeabilized LVC [16], confirming the key roles of PDE and PP in reducing cAMP phosphorylation in order to prevent the occurrence of rhythmic LCRs in LVC in the absence of $\mathrm{Ca}^{2+}$ overload.

Thus, protein phosphorylation synchronizes restitution mechanisms of spontaneous LCR occurrence in different loci throughout the cell, generating a rhythmic ensemble LCR $\mathrm{Ca}^{2+}$ signal of substantial amplitude, regardless of the cell type $[16,27]$.

\subsection{Phosphatase Regulation of Membrane Clock Proteins}

In addition to the effects on $\mathrm{SR} \mathrm{Ca}{ }^{2+}$ cycling changes in the AP-triggered $\mathrm{Ca}^{2+}$ transient and AP firing rate in response to phosphatase inhibition also results, in part, from increased $\mathrm{Ca}^{2+}$ influx via L-type $\mathrm{Ca}^{2+}$ channels, as evidenced by an increase in the $\mathrm{I}_{\mathrm{CaL}}$ amplitude and leftward shift of voltage dependence of $\mathrm{I}_{\mathrm{CaL}}$ activation (Figure 8). This effect could result from an increase in the phosphorylation state of the channel subunits, as was shown in LVC, in which $\beta$ AR stimulation increased the availability of L-type $\mathrm{Ca}^{2+}$ channels to activate in response to depolarization $[36,37]$. Recent evidence indicate that $\beta$-AR stimulation increases the availability of $\mathrm{Ca}_{\mathrm{V}} 1.2$ channels by enhancing its insertion from intracellular sites to the cell membrane [38].

Although PP2A binds directly to the C-terminal tail of $\mathrm{Ca}_{\mathrm{V}} 1.2$ [39] and PP1 regulates Cav1.2 channels in mouse VM $[30,40]$, there is no proof that PP1 directly interacts with $\mathrm{Ca}_{\mathrm{v}} 1.2$ channels. The acceleration of AP repolarization in response to PP inhibition that accompanies an increase in the AP firing rate (Table S3) might be explained, in part at least, by increased phosphorylation of $\mathrm{K}^{+}$channels due to signaling enabled by the AKAP (Yotiao) [41], enabling their increased availability to activate in response to membrane depolarization, as shown in LVC [42]. Recent studies also suggest that PKA also appears to phosphorylate HCN4 subunits to regulate funny current $\left(\mathrm{I}_{\mathrm{f}}\right)$, and that inhibition of PKA (which reduces phosphorylation, in addition to increasing cAMP), significantly impairs the $\beta$-AR stimulation-induced augmentation of $\mathrm{I}_{\mathrm{f}}$ current in isolated murine SANC [43].

PPs can regulate pacemaker activity directly and indirectly via impacting other clock functions. We have previously demonstrated that even a small increase in $\left[\mathrm{Na}^{+}\right]_{i}$ in response to $\mathrm{Na}^{+} / \mathrm{K}^{+}$pump inhibition by the digitalis glycoside (digoxigenin) perturbs SANC automaticity via impacting numerous coupled-clock mechanisms by producing changes in $\mathrm{Na}^{+}$and $\mathrm{Ca}^{2+}$ electrochemical gradients [44]. A subsequent numerical modeling study [45] validated these experimental results. Additionally, like the modulation of SERCA2A Ca ${ }^{2+}$ pumping by phosphorylation of PLB that modulates SERCA2A $\mathrm{Ca}^{2+}$ pumping, phosphorylation of phospholemman modulates $\mathrm{Na}^{+} / \mathrm{K}^{+}$pump activity $[46,47]$. Of note, PP1 is a negative regulator of phospholemman phosphorylation [48]. In other terms, PP1 activation acts as a break on the regulation of the coupled-clock system mechanisms driven by $\mathrm{Na}^{+}$ and $\mathrm{Ca}^{2+}$ electrochemical gradients.

4.5. Numerical Model Simulations of Biophysical Effects of Phosphatase-Dependent Regulation of Coupled-Clock System in SANC

A numerical model of SANC, which configures pacemaker cell function as a coupled system of $\mathrm{Ca}^{2+}$ and $\mathrm{M}$ clocks [22], quantitatively predicated the biophysical effects of protein phosphatase inhibition observed in our experiments. Model simulations (Figure 9) predicted the experimentally observed increase in the AP firing rate and occurrence of earlier and stronger diastolic $\mathrm{Ca}^{2+}$ release in the context of increases in the $\mathrm{SR} \mathrm{Ca}^{2+}$ pumping rate and $\mathrm{I}_{\mathrm{CaL}}$, mimicking the experimental result of increased protein phosphorylation and 
increased $\mathrm{I}_{\mathrm{CaL}}$ amplitude by CyA (Figures 3 and 8). In other words, we included in the model the experimentally measured effects of phosphorylation to increase the SR $\mathrm{Ca}^{2+}$ pumping rate and $\mathrm{I}_{\mathrm{CaL}}$ amplitude, and the model predicted the experimentally observed changes in AP firing rate as well as earlier and stronger diastolic LCR signal, a major feature of the coupled-clock mechanism, observed experimentally (Figure 7).

An important insight from our numerical modeling that cannot be obtained experimentally in AP firing SANC is that the biophysical mechanism of phosphatase-dependent regulation includes earlier and stronger activation of the respective diastolic inward $\mathrm{I}_{\mathrm{NCX}}$, which, in turn, accelerates diastolic depolarization, ultimately accounting for the observed increase in spontaneous AP firing rate (Figure 9B).

Importantly, the observed AP firing rate increase is fully quantitatively explained only when protein phosphorylation of both clocks is increased, i.e., when the $\mathrm{I}_{\mathrm{CaL}}$ increase is combined with SR $\mathrm{Ca}^{2+}$ pumping rate increase, and does not require changes in $\mathrm{I}_{\mathrm{f}}$, either via shifts in the voltage of its half-maximum activation (i.e., cAMP-dependent mechanism) [33] or via an increase in $\mathrm{I}_{\mathrm{f}}$ conductance [19].

That a major increase in RyR opening rate $\left(\mathrm{k}_{\mathrm{s}}\right)$, simulating possible effects of RyR phosphorylation has only a minor effect on the AP firing rate (Figure S3) is surprising and counterintuitive when taking into account that an increase in $\mathrm{k}_{\mathrm{s}}$ actually decreases the AP firing rate. This apparent paradox can be explained on the basis of the coupled-clock theory: the AP rate is actually determined by the coupled-clock ticking, i.e., by the kinetics of SR refilling with $\mathrm{Ca}^{2+}$ but not by the RyR release per se. Our simulations show that if RyRs release $\mathrm{Ca}^{2+}$ prematurely (simulated via higher $\mathrm{k}_{\mathrm{s}}$ in our model), the AP firing rate slows down. In other words, a stronger, premature $\mathrm{Ca}^{2+}$ release interferes with $\mathrm{SR} \mathrm{Ca}^{2+}$ refilling [49] and slows clock ticking. This inhibition of SERCA2A Ca ${ }^{2+}$ pumping by an excessive amount of $\mathrm{Ca}^{2+}$ to be pumped may explain previous observations of a slower rate and arrhythmia caused: (i) by catecholaminergic polymorphic ventricular tachycardia (CPVT) in which RyR mutations result in excessive RyR release [50] and also (ii) by "leaky" RyR, producing excessive $\mathrm{Ca}^{2+}$ release in the presence of ryanodine [51].

Finally, it is important to note that the purpose of introducing numerical modeling into the present study was to demonstrate that phosphatase-dependent regulation of AP firing rate is executed via a coupled-clock mechanism. Other types of numerical modeling, e.g., improvements of the prototype model in Yaniv et al. [52], are required to link the complex biochemical reactions including the detailed phosphorylation/de-phosphorylation kinetics to the biophysical mechanisms and AP firing rate described in the present study.

\section{Summary}

In summary, the combined effects of PP inhibition are to increase basal phosphorylation of both SR proteins (PLB, RyR) and the surface membrane proteins $\left(\mathrm{I}_{\mathrm{CaL}}, \mathrm{I}_{\mathrm{K}}\right)$ that modulate the basal state clock coupling and the spontaneous AP firing rate. The main functional effects of phosphorylation on both $\mathrm{M}$ and $\mathrm{Ca}^{2+}$ clock proteins is an increase in the size and an earlier occurrence of spontaneous RyR-generated LCRs (i.e., ensemble $\mathrm{Ca}^{2+}$ signal beneath the surface membrane) during diastolic depolarization, which shifts the acceleration of diastolic depolarization to earlier times, leading to a reduction in the AP cycle length [32]. The reduction in the LCR period, regulated by the entrainment of coupledclock functions, predicts the reduction in AP cycle length (for a review see $[1,53]$.Thus, basal PP activities reduce the extent to which clock molecules are phosphorylated in the basal state, suppressing the basal AP firing rate; basal PP activity, and basal PDE activity [11] act in concert to prevent excessive basal cAMP activation of PKA and CaMKII protein kinase activity, thereby limiting excessive basal phosphorylation of molecules that maintain cell $\mathrm{Ca}^{2+}$ homeostasis. The net result maintains the basal AP firing rate well below its maximum, enabling rapid, robust responses to external input aimed at affecting the AP firing rate. In other words, PP and PDE activities comprise a "double braking system" (Figure 1) on the feed-forward signaling of $\mathrm{Ca}^{2+}$-cAMP-PKA signaling that drives the SANC pacemaker function: PDEs are the "front brakes" and phosphatases are the 
"rear brakes" of the coupled-clock. In response to $\beta$-adrenergic stimulation, this "double breaking system" becomes partially overpowered, enabling cAMP and clock protein phosphorylation levels to increase. However, an increase in PKA-dependent phosphorylation further elevate PDE [54] and likely PP activities providing powerful negative feedback for cAMP signals and preventing excessive increases in cAMP and protein phosphorylation to limit the magnitude of the functional response to $\beta$-adrenergic receptor stimulation.

Supplementary Materials: The following are available online at https://www.mdpi.com/article/ 10.3390/cells10113106/s1, Figure S1: Inhibition of PP1 and PP2A activity by CyA increases RyR phosphorylation at Ser2809 site, which is phosphorylated by both PKA and CaMKII. Figure S2: Representative confocal line-scan images of permeabilized SANC bathed in $150 \mathrm{nmol} / \mathrm{L}^{\left[\mathrm{Ca}^{2+}\right.}$ ] in control conditions and following 2-min superfusion with $100 \mathrm{nmol} / \mathrm{L}$ okadaic acid (OKA). Figure S3: Results of the model sensitivity analysis examining possible involvement of RyR phosphorylation in regulation of SANC AP firing rate by phosphatases (PP). Table S1: PP's and PP inhibitor's alternative names of transcripts measured in RT-QPCR. Table S2: Primers and probes used for RT-QPCR. Table S3: AP parameters of isolated SANCs before and after inhibition of PP activity by different concentrations of CyA $\left({ }^{*} p<0.05\right.$, Control vs CyA).

Author Contributions: S.T.S.: performed experiments in permeabilized cells, statistical analyses, writing, editing, and preparing MS for submission. Additional critical experiments after I.Z. left; I.Z. performed experiments in intact cells, analyses, contributed to writing and editing MS; Y.L. performed Western blots; Y.O.L. contributed to editing and literature review; A.E.L. and B.D.Z. performed cell isolation; K.V.T. performed RT-QPCR, primer selection, and analysis; A.Y. participated in MS preparation; D.R.R. performed Western blots and analysis; Y.S.T. performed RT-QPCR, primers selection and analysis; D.Y. performed immunostaining and analysis; T.M.V. organized and interpreted Western blots and analyses and contributed to editing and writing the MS; V.A.M. performed numerical modeling, design program for analysis, contributed to MS writing; E.G.L. conceptualized the project, coordinated the execution of diverse experiments, interpreted, wrote and edited MS. All authors have read and agreed to the published version of the manuscript.

Funding: This research was supported entirely by the Intramural Research Program of the NIH, National Institute on Aging.

Institutional Review Board Statement: The animal study was reviewed and approved by the Animal Care and Use Committee of the National Institutes of Health (protocol \#457-LCS-2024).

Informed Consent Statement: Not applicable.

Data Availability Statement: The raw data supporting the conclusions of this article will be made available by the authors without undue reservation.

Conflicts of Interest: The authors declare no conflict of interest.

\section{Abbreviations}

SAN: sinoatrial node; SANC, sinoatrial nodal cells; AC, adenylyl cyclase; AKAP, A-kinase-anchoring protein; $\mathrm{AP}$, action potential; $\beta$-AR, beta adrenoceptors; $\mathrm{CaMKII,} \mathrm{Ca}^{2+}$, calmodulin-dependent protein kinase II; CyA, calyculin A; DARPP-32, Dopamine- and cAMP-regulated phosphoprotein; $\mathrm{I}_{\mathrm{f}}$, funny current; $\mathrm{I}_{\mathrm{CaL}}$, L-type $\mathrm{Ca}^{2+}$ current; $\mathrm{g}_{\mathrm{CaL}}, \mathrm{I}_{\mathrm{CaL}}$ conductance; HCN, hyperpolarization-activated cyclic nucleotide-gated channel; I-1, protein phosphatase-1 Inhibitor 1; IBMX, isobutylmethylxanthine; KEPI, kinase C-enhanced PP1 inhibitor; LCR, local submembrane $\mathrm{Ca}^{2+}$ releases; LVC, left ventricular cardiomyocytes; NCX, $\mathrm{Na}^{+} / \mathrm{Ca}^{2+}$ exchanger; OKA, okadaic acid; PDE, phosphodiesterase; PKA, protein kinase A; PLB, phospholamban; PP, phosphoprotein phosphatase; PP1, protein phosphatase-1; PP2A, protein phosphatase-2A; RyR, ryanodine receptors; SR, sarcoplasmic reticulum. 


\section{References}

1. Lakatta, E.G.; Maltsev, V.A.; Vinogradova, T.M. A coupled SYSTEM of intracellular Ca ${ }^{2+}$ clocks and surface membrane voltage clocks controls the timekeeping mechanism of the heart's pacemaker. Circ. Res. 2010, 106, 659-673. [CrossRef] [PubMed]

2. Li, Y.; Sirenko, S.; Riordon, D.R.; Yang, N.; Spurgeon, H.; Lakatta, E.; Vinogradova, T.M. CaMKII-dependent phosphorylation regulates basal cardiac pacemaker function via modulation of local Ca2+ releases. Am. J. Physiol. Heart Circ. Physiol. 2016, 311, H532-H544. [CrossRef] [PubMed]

3. Vinogradova, T.M.; Lyashkov, A.E.; Zhu, W.; Ruknudin, A.M.; Sirenko, S.; Yang, D.; Deo, S.; Barlow, M.; Johnson, S.; Caffrey, J.L.; et al. High basal protein kinase A-dependent phosphorylation drives rhythmic internal $\mathrm{Ca}^{2+}$ store oscillations and spontaneous beating of cardiac pacemaker cells. Circ. Res. 2006, 98, 505-514. [CrossRef] [PubMed]

4. Vinogradova, T.M.; Zhou, Y.-Y.; Bogdanov, K.Y.; Yang, D.; Kuschel, M.; Cheng, H.; Xiao, R.-P. Sinoatrial node pacemaker activity requires $\mathrm{Ca}^{2+}$ /calmodulin-dependent protein kinase II activation. Circ. Res. 2000, 87, 760-767. [CrossRef] [PubMed]

5. Vinogradova, T.M.; Tagirova Sirenko, S.; Lakatta, E.G. Unique Ca(2+)-Cycling Protein Abundance and Regulation Sustains Local $\mathrm{Ca}(2+)$ Releases and Spontaneous Firing of Rabbit Sinoatrial Node Cells. Int. J. Mol. Sci. 2018, 19, 2173. [CrossRef]

6. Capel, R.A.; Terrar, D.A. The importance of $\mathrm{Ca}(2+)$-dependent mechanisms for the initiation of the heartbeat. Front. Physiol. 2015, 6, 80. [CrossRef]

7. Younes, A.; Lyashkov, A.E.; Graham, D.; Sheydina, A.; Volkova, M.V.; Mitsak, M.; Vinogradova, T.M.; Lukyanenko, Y.O.; Li, Y.; Ruknudin, A.M.; et al. Ca ${ }^{2+}$-stimulated basal adenylyl cyclase activity localization in membrane lipid microdomains of cardiac sinoatrial nodal pacemaker cells. J. Biol. Chem. 2008, 283, 14461-14468. [CrossRef]

8. Lyashkov, A.E.; Vinogradova, T.M.; Zahanich, I.; Li, Y.; Younes, A.; Nuss, H.B.; Spurgeon, H.A.; Maltsev, V.A.; Lakatta, E.G. Cholinergic receptor signaling modulates spontaneous firing of sinoatrial nodal cells via integrated effects on PKA-dependent $\mathrm{Ca}^{2+}$ cycling and $\mathrm{I}_{\mathrm{KACh}}$. Am. J. Physiol. Heart Circ. Physiol. 2009, 297, H949-H959. [CrossRef]

9. Vinogradova, T.M.; Bogdanov, K.Y.; Lakatta, E.G. beta-Adrenergic stimulation modulates ryanodine receptor Ca2+ release during diastolic depolarization to accelerate pacemaker activity in rabbit sinoatrial nodal cells. Circ. Res. 2002, 90, 73-79. [CrossRef]

10. Vinogradova, T.M.; Lakatta, E.G. Dual Activation of Phosphodiesterase 3 and 4 Regulates Basal Cardiac Pacemaker Function and Beyond. Int. J. Mol. Sci. 2021, 22, 8414. [CrossRef]

11. Vinogradova, T.M.; Sirenko, S.; Lyashkov, A.E.; Younes, A.; Li, Y.; Zhu, W.; Yang, D.; Ruknudin, A.M.; Spurgeon, H.; Lakatta, E.G. Constitutive phosphodiesterase activity restricts spontaneous beating rate of cardiac pacemaker cells by suppressing local $\mathrm{Ca}^{2+}$ releases. Circ. Res. 2008, 102, 761-769. [CrossRef]

12. Bender, A.T.; Beavo, J.A. Cyclic nucleotide phosphodiesterases: Molecular regulation to clinical use. Pharmacol. Rev. 2006, 58, 488-520. [CrossRef]

13. Conti, M.; Mika, D.; Richter, W. Cyclic AMP compartments and signaling specificity: Role of cyclic nucleotide phosphodiesterases. J. Gen. Physiol. 2014, 143, 29-38. [CrossRef]

14. Lüss, H.; Klein-Wiele, O.; Bokník, P.; Herzig, S.; Knapp, J.; Linck, B.; Müller, F.U.; Scheld, H.H.; Schmid, C.; Schmitz, W.; et al. Regional expression of protein phosphatase type 1 and 2A catalytic subunit isoforms in the human heart. J. Mol. Cell Cardiol. 2000, 32, 2349-2359. [CrossRef]

15. Lei, M.; Wang, X.; Ke, Y.B.; Solaro, R.J. Regulation of Ca2+ transient by PP2A in normal and failing heart. Front. Physiol. 2015, 6, 13. [CrossRef]

16. Sirenko, S.; Maltsev, V.A.; Maltseva, L.A.; Yang, D.; Lukyanenko, Y.; Vinogradova, T.M.; Jones, L.R.; Lakatta, E.G. Sarcoplasmic reticulum Ca cycling protein phosphorylation in a physiologic Ca milieu unleashes a high-power, rhythmic Ca clock in ventricular myocytes: Relevance to arrhythmias and bio-pacemaker design. J. Mol. Cell Cardiol. 2014, 66C, 106-115. [CrossRef]

17. Rodriguez-Martinez, M.; Arechiga-Figueroa, I.A.; Moreno-Galindo, E.G.; Navarro-Polanco, R.A.; Sanchez-Chapula, J.A. Muscarinic-activated potassium current mediates the negative chronotropic effect of pilocarpine on the rabbit sinoatrial node. Pflugers. Arch. 2011, 462, 235-243. [CrossRef]

18. Yaniv, Y.; Spurgeon, H.A.; Ziman, B.D.; Lyashkov, A.E.; Lakatta, E.G. Mechanisms that match ATP supply to demand in cardiac pacemaker cells during high ATP demand. Am. J. Physiol. Heart Circ. Physiol. 2013, 304, H1428-H1438. [CrossRef]

19. Accili, A.E.; Redaelli, G.; DiFrancesco, D. Differential control of the hyperpolarization-activated current (i(f)) by cAMP gating and phosphatase inhibition in rabbit sino-atrial node myocytes. J. Physiol.-Lond. 1997, 5003, 643-651. [CrossRef]

20. Yu, H.; Chang, F.; Cohen, I.S. Phosphatase inhibition by calyculin A increases i(f) in canine Purkinje fibers and myocytes. Pflugers. Arch. 1993, 422, 614-616. [CrossRef]

21. Ceulemans, H.; Bollen, M. Functional diversity of protein phosphatase-1, a cellular economizer and reset button. Physiol. Rev. 2004, 84, 1-39. [CrossRef]

22. Maltsev, V.A.; Lakatta, E.G. Synergism of coupled subsarcolemmal Ca2+ clocks and sarcolemmal voltage clocks confers robust and flexible pacemaker function in a novel pacemaker cell model. Am. J. Physiol. Heart Circ. Physiol. 2009, 296, H594-H615. [CrossRef]

23. Lukyanenko, Y.O.; Younes, A.; Lyashkov, A.E.; Tarasov, K.V.; Riordon, D.R.; Lee, J.; Sirenko, S.G.; Kobrinsky, E.; Ziman, B.; Tarasova, Y.S.; et al. $\mathrm{Ca}^{2+} /$ calmodulin-activated phosphodiesterase $1 \mathrm{~A}$ is highly expressed in rabbit cardiac sinoatrial nodal cells and regulates pacemaker function. J. Mol. Cell. Cardiol. 2016, 98, 73-82. [CrossRef] 
24. Kuschel, M.; Zhou, Y.Y.; Spurgeon, H.A.; Bartel, S.; Karczewski, P.; Zhang, S.J.; Krause, E.G.; Lakatta, E.G.; Xiao, R.P. beta(2)adrenergic cAMP signaling is uncoupled from phosphorylation of cytoplasmic proteins in canine heart. Circulation 1999, 99, 2458-2465. [CrossRef] [PubMed]

25. Bogdanov, K.Y.; Vinogradova, T.M.; Lakatta, E.G. Sinoatrial nodal cell ryanodine receptor and $\mathrm{Na}(+)-\mathrm{Ca}(2+)$ exchanger: $\mathrm{Molecular}$ partners in pacemaker regulation. Circ. Res. 2001, 88, 1254-1258. [CrossRef]

26. Vinogradova, T.M.; Zhou, Y.Y.; Maltsev, V.; Lyashkov, A.; Stern, M.; Lakatta, E.G. Rhythmic ryanodine receptor Ca ${ }^{2+}$ releases during diastolic depolarization of sinoatrial pacemaker cells do not require membrane depolarization. Circ. Res. 2004, 94, 802-809. [CrossRef]

27. Sirenko, S.; Yang, D.; Li, Y.; Lyashkov, A.E.; Lukyanenko, Y.O.; Lakatta, E.G.; Vinogradova, T.M. Ca(2)(+)-dependent phosphorylation of $\mathrm{Ca}(2)(+)$ cycling proteins generates robust rhythmic local $\mathrm{Ca}(2)(+)$ releases in cardiac pacemaker cells. Sci. Signal. 2013, 6, ra6. [CrossRef]

28. Yang, D.; Lyashkov, A.E.; Li, Y.; Ziman, B.D.; Lakatta, E.G. RGS2 overexpression or G(i) inhibition rescues the impaired PKA signaling and slow AP firing of cultured adult rabbit pacemaker cells. J. Mol. Cell Cardiol. 2012, 53, 687-694. [CrossRef]

29. Favre, B.; Turowski, P.; Hemmings, B.A. Differential inhibition and posttranslational modification of protein phosphatase 1 and 2A in MCF7 cells treated with calyculin-A, okadaic acid, and tautomycin. J. Biol. Chem. 1997, 272, 13856-13863. [CrossRef] [PubMed]

30. duBell, W.H.; Gigena, M.S.; Guatimosim, S.; Long, X.; Lederer, W.J.; Rogers, T.B. Effects of PP1/PP2A inhibitor calyculin A on the E-C coupling cascade in murine ventricular myocytes. Am. J. Physiol. Heart Circ. Physiol. 2002, 282, H38-H48. [CrossRef] [PubMed]

31. El-Armouche, A.; Bednorz, A.; Pamminger, T.; Ditz, D.; Didié, M.; Dobrev, D.; Eschenhagen, T. Role of calcineurin and protein phosphatase-2A in the regulation of phosphatase inhibitor-1 in cardiac myocytes. Biochem. Biophys. Res. Commun. 2006, 346, 700-706. [CrossRef]

32. Lyashkov, A.E.; Behar, J.; Lakatta, E.G.; Yaniv, Y.; Maltsev, V.A. Positive Feedback Mechanisms among Local Ca Releases, NCX, and ICaL Ignite Pacemaker Action Potentials. Biophys. J. 2018, 114, 1176-1189. [CrossRef]

33. DiFrancesco, D.; Tortora, P. Direct activation of cardiac pacemaker channels by intracellular cyclic AMP. Nature 1991, 351, 145-147. [CrossRef]

34. Mattiazzi, A.; Kranias, E.G. CaMKII regulation of phospholamban and SR Ca2+ load. Heart Rhythm 2011, 8, 784-787. [CrossRef]

35. Vedantham, V.; Galang, G.; Evangelista, M.; Deo, R.C.; Srivastava, D. RNA sequencing of mouse sinoatrial node reveals an upstream regulatory role for Islet-1 in cardiac pacemaker cells. Circ. Res. 2015, 116, 797-803. [CrossRef]

36. Catterall, W.A. Regulation of Cardiac Calcium Channels in the Fight-or-Flight Response. Curr. Mol. Pharmacol. 2015, 8, 12-21. [CrossRef]

37. Reuter, H.; Beeler, G.W., Jr. Calcium current and activation of contraction in ventricular myocardial fibers. Science 1969, 163, 399-401. [CrossRef]

38. Del Villar, S.G.; Voelker, T.L.; Westhoff, M.; Reddy, G.R.; Spooner, H.C.; Navedo, M.F.; Dickson, E.J.; Dixon, R.E. beta-Adrenergic control of sarcolemmal CaV1.2 abundance by small GTPase Rab proteins. Proc. Natl. Acad. Sci. USA 2021, 118, e2017937118. [CrossRef]

39. Davare, M.A.; Horne, M.C.; Hell, J.W. Protein phosphatase 2A is associated with class C L-type calcium channels (Ca(v)1.2) and antagonizes channel phosphorylation by cAMP-dependent protein kinase. J. Biol. Chem. 2000, 275, 39710-39717. [CrossRef]

40. Dai, S.; Hall, D.D.; Hell, J.W. Supramolecular assemblies and localized regulation of voltage-gated ion channels. Physiol. Rev. 2009, 89, 411-452. [CrossRef]

41. Ercu, M.; Klussmann, E. Roles of A-Kinase Anchoring Proteins and Phosphodiesterases in the Cardiovascular System. J. Cardiovasc. Dev. Dis. 2018, 5, 14. [CrossRef]

42. Chen, L.; Kurokawa, J.; Kass, R.S. Phosphorylation of the A-kinase-anchoring protein Yotiao contributes to protein kinase A regulation of a heart potassium channel. J. Biol. Chem. 2005, 280, 31347-31352. [CrossRef]

43. Liao, Z.; Lockhead, D.; Larson, E.D.; Proenza, C. Phosphorylation and modulation of hyperpolarization-activated HCN4 channels by protein kinase A in the mouse sinoatrial node. J. Gen. Physiol. 2010, 136, 247-258. [CrossRef]

44. Sirenko, S.G.; Maltsev, V.A.; Yaniv, Y.; Bychkov, R.; Yaeger, D.; Vinogradova, T.M.; Spurgeon, H.A.; Lakatta, E.G. Electrochemical $\mathrm{Na}+$ and $\mathrm{Ca} 2+$ gradients drive coupled-clock regulation of automaticity of isolated rabbit sinoatrial nodal pacemaker cells. Am. J. Physiol. Heart Circ. Physiol. 2016, 311, H251-H267. [CrossRef]

45. Morotti, S.; Ni, H.; Peters, C.; Rickert, C.; Asgari-Targhi, A.; Sato, D.; Glukhov, A.; Proenza, C.; Grandi, E. Intracellular Na(+) Modulates Pacemaking Activity in Murine Sinoatrial Node Myocytes: An In Silico Analysis. Int. J. Mol. Sci. 2021, $22,5645$. [CrossRef]

46. Despa, S.; Tucker, A.L.; Bers, D.M. Phospholemman-mediated activation of Na/K-ATPase limits [Na]i and inotropic state during beta-adrenergic stimulation in mouse ventricular myocytes. Circulation 2008, 117, 1849-1855. [CrossRef]

47. Pavlovic, D.; Fuller, W.; Shattock, M.J. Novel regulation of cardiac Na pump via phospholemman. J. Mol. Cell Cardiol. 2013, 61, 83-93. [CrossRef]

48. El-Armouche, A.; Wittkopper, K.; Fuller, W.; Howie, J.; Shattock, M.J.; Pavlovic, D. Phospholemman-dependent regulation of the cardiac Na/K-ATPase activity is modulated by inhibitor-1 sensitive type-1 phosphatase. FASEB J. 2011, 25, 4467-4475. [CrossRef] 
49. Tada, M.; Kirchberger, M.A.; Repke, D.I.; Katz, A.M. The stimulation of calcium transport in cardiac sarcoplasmic reticulum by adenosine $3^{\prime}: 5^{\prime}$-monophosphate-dependent protein kinase. J. Biol. Chem. 1974, 249, 6174-6180. [CrossRef]

50. Neco, P.; Torrente, A.G.; Mesirca, P.; Zorio, E.; Liu, N.; Priori, S.G.; Napolitano, C.; Richard, S.; Benitah, J.-P.; Mangoni, M.; et al. Paradoxical Effect of Increased Diastolic Ca2+ Release and Decreased Sinoatrial Node Activity in a Mouse Model of Catecholaminergic Polymorphic Ventricular Tachycardia. Circulation 2012, 126, 392-401. [CrossRef]

51. Rubenstein, D.S.; Lipsius, S.L. Mechanisms of automaticity in subsidiary pacemakers from cat right atrium. Circ. Res. 1989, 64, 648-657. [CrossRef] [PubMed]

52. Yaniv, Y.; Ganesan, A.; Yang, D.; Ziman, B.D.; Lyashkov, A.E.; Levchenko, A.; Zhang, J.; Lakatta, E.G. Real-time relationship between PKA biochemical signal network dynamics and increased action potential firing rate in heart pacemaker cells Kinetics of PKA activation in heart pacemaker cells. J. Mol. Cell. Cardiol. 2015, 86, 168-178. [CrossRef] [PubMed]

53. Vinogradova, T.M.; Lakatta, E.G. Regulation of basal and reserve cardiac pacemaker function by interactions of cAMP-mediated PKA-dependent Ca2+ cycling with surface membrane channels. J. Mol. Cell Cardiol. 2009, 47, 456-474. [CrossRef] [PubMed]

54. Sette, C.; Conti, M. Phosphorylation and activation of a cAMP-specific phosphodiesterase by the cAMP-dependent protein kinase. Involvement of serine 54 in the enzyme activation. J. Biol. Chem. 1996, 271, 16526-16534. [CrossRef] 